\title{
ADUBAÇĀO FOSFATADA NA CULTURA DO MILHO (Zea mays L.), EM DOIS SOLOS SOB VEGETAÇÃO DE CERRADO NO ESTADO DE GOIÁS
}

\author{
LUIZ CARLOS VALLADARES BORGES
}

Orientador: Francisco de Assis Ferraz de Mello

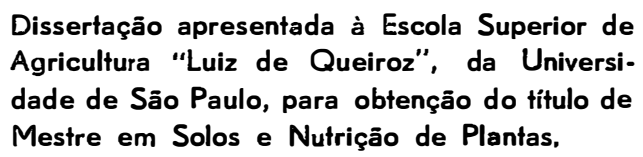

PIRACICA B A

Estado de São Paulo - Brasil

Junho, 1978 
Oferecimento:

A minha esposa Ana Amélia e meus filhos;

Jose Valladares Neto, Ana Claudia e Luciana,

Gratidão:

A meus pais Alice e José Valladares

Aos mestre,

Aos amigos. 


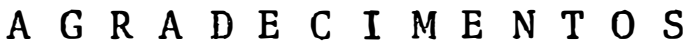

A Universidade de São Paulo e E.S.A. "Luiz de Queiroz" represen tadas pelos professores que propiciaram os ensinamentos deste curso de Pós graduação em Solos e Nutrição de Plantas.

A Universidade Federal de Goias atravēs da Escola de Agronomia e Veterinaria e a Secretaria da Agricultura do Estado de Goiās, por haverem permitido meu afastamento para o Pos-Gra duação.

A Empresa Goiana de Pesquisa Agropecuária, por haver propiciado os meios para a execução deste trabalho.

Ao Professor Francisco A.F. de Mello pela sua orientação e amiza de.

Ao Professor Roberto $S$. de Moraes do Departamento de Platemática e Estatística da E.S.A. "Luiz de Queiroz" pelos cálculos esta tisticos.

Aos Colegas do Departamento de Agricultura da Escola de Agronomia e Veterinária da U.F.G. pelos auxtios prestalos.

A Equipe do Projeto Solos da EMGOPA pela colabo ração na montagem, condução e coleta dos dados.

A todos que colaboraram, compreenderan e estimularam nos momentos dificeis e que tornaram este trabalhs em realidade. 


\section{N D I C E}

Pàgina

$1-\operatorname{RESUMO} \ldots \ldots \ldots \ldots \ldots \ldots \ldots \ldots \ldots \ldots \ldots \ldots \ldots \ldots \ldots \ldots \ldots$

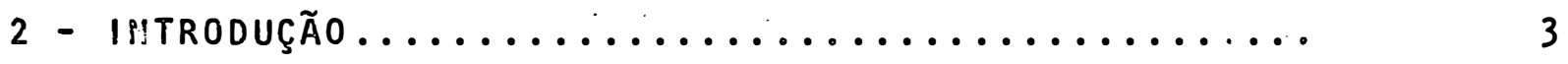

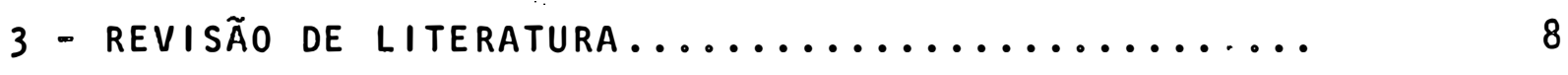

4 - MATERIAIS E METODOS....................... 17

4.1 Considerações gerais................. 17

4.2 - Experimento de Goiânia................. 21

4.3 - Experimento de Santa Helena............. 22

5 - RESULTAdOS E DISCUSSĂO ..................... 23

5.1 - Resultados do primeiro ano.............. 23

5.2 - Resultados do segundo ano.............. 26

5.2 .1 -Experimento de Goiânia........... 26

5.2 .2 - Experimento de Santa Helena........ 31

5.3 - Considerações finais................... 35

6 - CONCLUSชes............................. 40

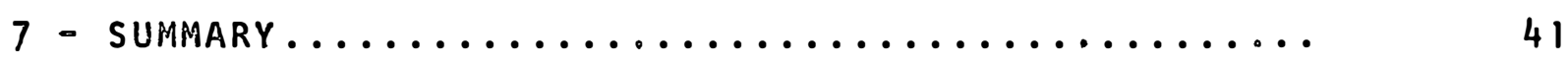

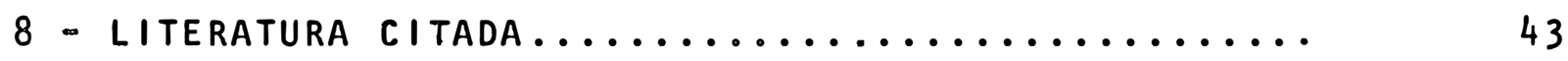

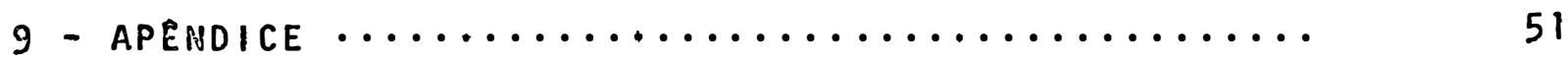


1 - RESUMO

Dois experimentos de campo em solos representativos da exploração agrícola sob vegetação de "cerrado" foram instalados próximos às cidades de Goiânia (LVE) e Santa Helena (LR) no Estado de Goiás (Brasil). No primeiro ano foi aplicado o fosfato natural de Catalão que é uma apatita com $38,2 \%$ de $\mathrm{P}_{2}{ }^{0_{5}}$ total e com uma solubilidade em ácido cítrico a $2 \%(1: 100)$ igual a $3,1 \%$, nas doses de $0,150,300,600$ e $1.200 \mathrm{~kg}$ de $\mathrm{P}_{2}{ }^{0} 5$ total/ha, a 1anço. No segundo ano, utilizou-se sobre as doses acima, uma adu bação no sulco com o superfosfato triplo nas doses de $0,50,100$ e $200 \mathrm{~kg}$ de $\mathrm{P}_{2} \mathrm{O}_{5} / \mathrm{ha}$. 
A adubação com o fosfato de Catalão nas doses acima não deu resposta significativa no primeiro ano nas duas localidades para a cultura do milho (Zea mays L.). No segundo ano houve um efeito significativo em Goiânia. Em Santa Helena não houve efeito significativo para o fosfato natural de Catalão.

o superfosfato triplo provocou um efeito marcante na produção, o que indica que nos primeiros anos de exploração desses dois "tipos de cerrados", há uma necessidade de aplicação de uma fonte solúvel de $P$ no sulco. 
A área originalmente coberta pela vegetação de cerrado no Brasil é cerca de 180 milhões de hectares. Esta dimensão equivale a aproximadamente $21 \%$ do territörio brasileiro. o Estado de Goiás possui, em "cerrado", $30 \%$ da distribuição percentual no País (EḾBRAPA-CPAC, 1976). Devido a proximidade dos grandes centros consumidores, preço da terra e possibilidade de mecanização, entre outros fatores, e atualmente uma das alternativas mais viáveis para a incorporação de novas áreas ao processo produtivo. 
Sob está vegetação predominam os solos classificados como latossolo (Oxisol, na classificação americana). Do ponto de vista da utilização agropecuāria nesta ārea, destaca-se dentro dos latossolos: o latossolo roxo (LR), o latossolo vermelho escuro (LVE) e o latossolo vermelho amarelo (LVa), que são geralmen te profundos, ācidos e pobres em elementos nutritivos as plantas (EMBRAPA-CPAC, 1976a), e FREITAS e SILVEIRA, 1976)。 Entre esses elementos, o fósforo e, sem dúvida alguma, um dos fatores que mais tem limitado a produção das principais culturas anuais, con forme se pode observar nos trabalhos coletados na Bibliografia A nalítica do Cerrado (EMBRAPA-CPAC, 1976b), no trabalho de ALMEIDA Neto (1975), citação de MALAVOLta (1977) e no estudo de campos e GOMES (1976) que analisaram um grande nümero de experimentos com milho, verificando as interações $\mathrm{N}, \mathrm{P}, \mathrm{K}$ e o seu efeito isolado. Sua importância para as pastagens pode ser vista em REID e JUNG (1975) que citam as palavras de Underwood, 1966: "There is no doubt that phosphorus deficiency is the most widespread and economically important of all the mineral disabilities affecting grazing livestock ${ }^{\circ}$.

A cultura do milho (zea mays L.) é a segunda área cul tivada no Estado, estando abaixo sómente da cultura do arroz (Ory za sativa L). De acordo com o Plano de Ação da Secretaria da Agricultura do Estado de Goiás (1975), pode-se observar nitidamente a cstabilização da área de arroz, sendo que a ảrea de milho que nos anos agrícolas $17 / 73$ a $76 / 77$ aumentou em 50\%, possuindo, atualmente uma área plantada de 685.00 ha, com uma produção de 1.274.100 $t$, segundo dados do IBGE (1977). 
o regime pluviométrico da região, é talvez, um dos maiores responsáveis por tal fato, devido aos "veranicos", que são ocorrências de períodos sem chuva durante a estação chuvosa e que acontecem durante o ciclo das culturas, prejudicando principalmente o arroz de sequeiro, enquanto que a cultura do milho sofre menor influência.

Na região do Brasil Central ocorrem vārias jazidas de calcārio conforme citação de SOARES et alii (1975) e de rochas fosfatadas como as de Patos de Minas, Tapira, Araxá, Abaeté, Coro mandel, Catalão e outras (PARADA e ANDRADE, 1976 e EIM-Engenharia para a Indústria Mineral S.A., 1977a). A recente exploração da jazida do fosfato natural de Catalão que se encontra no sudeste do Estudo de Goiás, poderá minimizar o custo de um dos fatores mais importantes na produção agrícola nesta área.

Existe ainda a Politica Governamental de estimular programas especiais de desenvolvimento do cerrado e também confor me expresso no Plano Nacional de Fertilizantes e Calcärio Agrico$1 a$ (BRASIL, 1974) há uma programação visando a rełução das importações e autosuficiência em fertilizantes. A situação atual é o grande aumento em volume importado e a diminuição na relação produto nacional fosfático/importado, que em 1961 era de $786 \%$ e passou em 1974 (atë junho) para $15,9 \%$, conforme trabalho de CARVALHO e ARAUJo (1974), citando os dados do Sindicato da Indústria de Adubos e Colas do Estado de São Paulo. Estes dispêndios com a importação têm causado fortes pressões na balança de pagamentos do Pais. 
Entretanto, para a utilização destes fosfatos naturais brasileiros, temos alguns problemas sérios a resolver, dos quais podemos enumerar:

a) - dificuldades na fabricação de fosfatos solúveis devido a falta de conhecimento em tecnologia e de preços competitivos com o material importado;

b) - falta de conhecimento agronômico do efeito do material nacional aplicado como fonte natural.

Trabalho recente de revisäo sobre os fosfatos naturais foi realizado por BRAGA (1970). Além de um número relativamente pequeno de experimentos, principalmente com as fontes recém descobertas e exploradas, observa-se uma porcentagem alta em trabalhos de laboratório e a preocupação fundamental nos trabalhos de campo para a competição entre fontes. Deve-se notar atentamen te que a recomendação geral no Brasil e outros países e de que o fosfato natural deve ser aplicado sempre a lanço, com a finalidade de se diminuir as doses de fösforo solúvel no sulco, barateando assim o custo das adubações (BRAGA, 1970 p. 13-17).

Partindo desta premissa, onde existe uma grande lacuna na bibliografia brasileira, o presente trabalho feito em dois tipos de solos representativos da área agrícola cultivada do cerrado (LVE e LR), utilizando como planta teste o milho, teve como objetivos básicos: 
a) - verificar o efeito dos niveis de uma fonte solúvel de fósforo aplicada no sulco, sobre diferentes níveis do fosfato natural de Catalão aplicado anteriormente a lan ço:

b) - obter a resposta em produção do efeito fertilizante do fosfato de Catalão a 1 anço;

c) - medir seu efeito residua1;

d) - comparar a produção nos vários níveis de fósforo entre as fontes de fosfato de Catalão a lanço com o superfosfato triplo no sulco de plantio;

e) - obter coeficientes técnicos que servirão para a avaliação econômica das fontes, ou da combinação das mesmas. 
Dentre os trabalhos em que se estudaram a solubilização dos fosfatos com soluções extratoras podemos citar o de CATANI e NASCIMENTO (1952), CATANI, NASCIMENTo e costa (1956) que determinaram. os teores solúveis de diversos fosfatos em ácido citrico a $2 \%$ e que mostraram uma escala de variação entre as diferentes fon tes de fosfato.

BRASIL SOBRINHO et alii (1965) observaram que os diferentes fosfatos aumentam sua solubilidade quando a razão fertilizante: solução extratora (ácido cítrico a 2\%) vai de $1: 100$ até $1: 1.000$. Os fosfatos mais solúveis atingiram a mais alta solubi- 
lidade na razão $1: 100$, enquanto os de média solubilidade a $1: 400$ e os menos solúveis ainda continuavam a subir até a relação $1: 100$

o estudo da influência da granulometria na solubilidade dos fosfatos naturais foi estudada por CATANI e NASCIMENTO (1954), e pelos trabalhos de Ilchenko e Guimarães além do de Campos citados por BRAGA (1970). A solubilidade aumenta com o grau de finura do material até um certo limite.

CATANI (1970), trabalhando com o extrator ácido cittrico a 2\% na razão $1: 200$ conclui que o fósforo $\left(\mathrm{P}_{2}{ }^{0_{5}}\right)$ do fosfato tricälcico puro e o da farinha de ossos degelatinado, são completamente solúveis neste extrator e o número de equivalentes miligramas de hidrogenio existente em $200 \mathrm{~m} 1$ desta solução corresponde ao dobro do necessário, para a dissolução tanto de $1 \mathrm{~g}$ de fosfato tricálcico como de 1 g de fluofosfato de cálcio, que è o componen te fosfático principal das rochas fosfatadas. Portanto, adotando-se este extrator, o teor solubilizado poderia ser expresso como equivalente ao contido no fosfato tricälcico. Neste mesmo tra balho, referindo-se aos extratores, o autor diz textualmente "e quase impossível uma interpretação agronômica da eficiência dos fosfatos naturais, baseada na solubilidade em solução de ácido cí trico a 2\%". Outros métodos referindo-se a solubilidade foram testados, como o de CATANI e PELEGRINO (1960) que estudaram os processos de agitação utilizando vários fosfatos e não encontraram diferenças entre o metodo de Wagner com outros processos de agitação horizontal. 
Utilizando o método de Neubaner, CATANI e GLóRIA (1961), verificaram a disponibilidade de fósforo em diversas fontes, utilizando o arroz (oryza sativa L.) como planta teste. o resultado do exame da planta pela quantidade de fósforo absorvida forneceu uma indicação da diferença em solubilidade existente entre as fontes. Entretanto, trabalho de BRAGA e YAHNER (1968b), que estu daram os teores de $P$ na folha de milho, colhidas de um experimen to de campo, onde se testou doses do superfosfato simples e do fosfato de Araxá, observaram que na mesma dose das duas fontes (com referência aos teores solúveis), os níveis na folha eram diferentes conforme as fontes, cabendo ao fosfato de Araxá os maiores números. Trabalho de LUTz (1971) que comparou o fosfato da Flörida parcialmente acidulado (20\%) com o totalmente acidulado a 100\% do necessário para converter a rocha fosfatada para superfosfato concentrado, verificou que o teor de $P$ na folha do milho no primeiro ano não era afetada no seu teor pelas fontes, mas nos dois cultivos subsequentes, apareceram diferenças evidentes.

CARVALHO e.t alii (1969) estudaram as relações entre algumas espêcies dos generos Aspergilzus e Penicillium em três fos fatos insolúveis, determinando quantitativamente o fósforo solubi lizado e o imobilizado. Apesar das vārias linhagens estudadas de monstrarem alta capacidade solubilizadora, algumas só conseguiam retirar determinados tipos de fosfatos, sendo que outras foram in capazes de solubilizar outros tipos. MELlo et ali $i$ (1974) verificaram o efeito residual de diferentes fosfatos com o auxilio do $\mathrm{P}^{32}$, do método de Neubauer e do método do Aspergizlus niger, 
sendo que os resultados de laboratorio, concordaram com os dados de produção obtidos no experimento de campo.

Naturalmente, estes tipos de trabalhos apresentados são importantes para uma seleção preliminar das diferentes fontes de fosfatos. BRAGA e YAHNER (1968a) dizem que o conceito de solubilidade "è um artificialismo do homem para assemelhar em laboratório as condições que ocorrem no campo". Nos trabalhos da EMBRAPA-CPAC (1976a), FEITOSA et ali $i$ (1977) e ALMEIDA NETO et ali $i$ (nao publicado), pode-se observar que a solubilidade da bauxita fosforosa do Maranhão é baixa em ácido cĩtrico a $2 \%$ na relação $1: 100$, mas e bem aproveitada pelos vegetais que dão produções me1hores do que com outros fosfatos mais "solúveis" neste extrator.

Em trabalho de revisão sobre os resultados experimentais de fontes de fósforo, BRAGA (1970), ressalta a importância da interaçao solo X planta X fertilizante, mostrando que a solubilidade dos fosfatos depende de uma série de fatores:

a) - extrator (tipo e relação extrator: rocha fosfatada);

b) - solo (teor de fósforo presente, reação do solo que seria o $\mathrm{pH}$, teor de ferro livre e matéria orgânica);

c) - tipo de fosfato referindo-se ao grau de finura e teor de fluor;

d) - do modo de aplicação do fertilizante, se a lanço ou 1ocalizado; 
e) - da capacidade de aproveitamento do fósforo pelos vegetais. Pode variar entre culturas conforme nos mostra o trabalho de MANOILOVIC e ZERAVICA (1976) e até entre cultivares conforme trabalho da EMBRAPA-CPAC (1976a p. 83) feito com arroz.

Além desses fatores, outras variáveis podem ser acres cidas como as citadas por CATANI (1970), CARVALHO et alii

e $\operatorname{EIM~(1977b),~listadas~a~seguir:~tipo~de~rede~cristalina~}$ $\operatorname{com}$ suas impurezas e incrustações, condições climáticas, teor de argi 1a, formas de fosfatos, microorganismos do solo, ärea superficial dos grãos (no sentido da ärea externa e da porosidade), além da rugosidade dos grãos de fosfato.

Em função desta complexidade de fatores é que os tra balhos experimentais preferidos devem ser os biológicos. Devido a isto os resultados são algumas vezes inesperados deixando o pesquisador sem uma explicação para certos fatos. Daí a necessidade da intensificação dos trabalhos em condição de campo para fornecer subsídios na explicação de alguns fatos. 0 efeito residual das diversas fontes de fosfatos são muito pouco estudadas, sendo de grande valia seu conhecimento em diferentes tipos de solos e cultivares, para que se possa recomendar adequadamente as doses de fertilizantes, maximizando assim o lucro dos agricultores. 
BRAGA (1970) afirma que não se deve aplicar formas de fosfatos solúveis em água em solos com alto teor de óxidos de fer ro e-de alumínio, uma vez que aplicações localizadas com estas fontes, normalmente são feitas com o objetivo de conseguir um melhor aproveitamento deste fertilizante. Todavia o assunto é pólê mico e trabalho da EMBRAPA-CPAC (1976, p. 56-58) nos mostra que com adubações pesadas de superfosfato triplo (1.280 kg de $\left.\mathrm{P}_{2} \mathrm{O}_{5} / \mathrm{ha}\right)$ num LVE textura argilosa produziu colheitas estáveis de milho após seis cultivos ( 3 anos), portanto com um longo efeito residual. Essa disponibilidade de fósforo acumulada e importante para as culturas seguintes nos locais onde a fertilização vem sendo prati cada por vários anos (STELLY e MORRIS, 1953 ; ENSIMINGER e PEARSON, 1957 e SMITH e PESEK 1962).

Sabe-se que as plantas exigem nos primeiros estägios de crescimento, uma resposta mais marcada ao fósforo solúvel no sulco de plantio onde suas necessidades iniciais seriam satisfeitas, porëm com a expansão do sistema radicular, maior uso do fósforo residual ou nativo será feito pelas plantas (OLSEN, 1953 e KAMPA RATH, 1969).

Segundo OLSEN (1953) o valor residual do fósforo apli cado é menor em solos ácidos, principalmente naqueles com grandes quantidades de sesquióxidos e caolinita.

No trabalho de SHELTON e COLEMANN (1968) eles dizem que e prätica comum se adicionar 50 a $60 \mathrm{~kg}$ de $\mathrm{P}_{2} \mathrm{O}_{5} / \mathrm{ha}$ anualmente, em consequência do pequeno valor residual dos adubos fosfatadọs que não seriam aproveitados pelas plantas. 
0 efeito residual dos fosfatos depende da fonte do nutriente empregado e DOLL, MILLER e FREEMAN (1969), comparando o superfosfato e o fosfato de rocha em experimento de campog após 27 anos, encontraram uma maior disponibilidade inicial do superfosfato solúve1, devido as transformações no próprio solo. Tambëm MOSCHLER e KREBS (1929), encontraram um fósforo residual $\overrightarrow{4}$ vezes maior para o superfosfato em relação ao fosfato de rocha. 0 mesmo efeito residual foi comprovado por CALDWELL et alii - (1956) que utilizaram o $\mathrm{P}^{32}$.

0 tipo de solo é bastante importante e CAMPBELL (1965) cita os trabalhos de 01 sen e Watanabe que mostram que a necessida de da resposta da cevada de acordo com a concentração de fósforo no solo requer, 3,9 vezes mais fósforo num solo argiloso do que num franco arenoso.

Um exaustivo trabalho de revisão dos resultados de en saios brasileiros com fontes de fósforo fọi feito por BRAGA (1970) tomando uma série de experimentos feitos principalmente nos Estä dos de Minas Gerais e são Paulo. Outros trabalhos mais recentes podem ser acrescentados como o de MELLO et alii (1974) que estuda ram o efeito residual de três fontes, em cana de açūcar; de GOEPFERT (1974); vārios ensaios no Inventārio Tecnológico do Arroz (EMBRAPA-CNPAC, 1975), EMBRAPA-CPAC (1976 p。59-64) testando três fontes em Brachiaria decumbens e um ensaio preliminar com 11 fontes de fósforo na cultura do trigo. 
A anālise geral destes vārios trabalhos competindo fon tes de fósforo no Brasil é a de que as fontes mais solúveis de um modo geral são as mais produtivas, principalmente nos primeiros anos e quando se considera o teor de $\mathrm{P}_{2} \mathrm{O}_{5}$ total nos fosfatos. En tretanto os fosfatos naturais têm mostrado um efeito residual com tendência a melhorar a longo prazo e dão efeitos iguais ou pouco menores quando as doses são maiores ou se considera o $\mathrm{P}_{2} \mathrm{O}_{5}$ solú vel dos fosfatos nas competições. Alguns dados, com a variação de locais, culturas, fontes o solos conforme jā abordados anterior mente, têm dado alguns resultados inesperados fugindo desta ava1 iação geral.

os trabalhos publicados com o fosfato de Catalão são em pequeno nümero podendo-se citar o de CARVALHO (1974a) que trata dos aspectos geológicos e petrográficos do depösito do complexo de Catalão I ; CARVALHo (1974b) referindo-se aos recursos mine rais deste complexo e CARVALHO e ARAUJO (1974) que traçam as perspectivas do aproveitamento econômico deste depósito. Sabe-se que a jazida é semelhante ao complexo ígneo de Araxă, tendo como principais minerais fosfáticos que predominam em mais de $85 \%$ do minério, a fluor-apatita e a dalhita. 0 teor de $\mathrm{P}_{2} \mathrm{O}_{5}$ total, in natura, é superior a $10 \%$. A estimativa da jazida está entre 120 e 150 milhões de toneladas.

Estudo do comportamento desse fosfato para a produção do superfosfato simples, nas condições de laboratório, partindo do material concentrado com teor de $40 \%$ de $\mathrm{P}_{2} \mathrm{O}_{5}$ total, foi execu- 
tado pela EIM (1977c) e se obteve, com a melhoria da gramulometria, após 10 dias de maturação, um material de qualidade elevada.

Trabalho de vasos em casa de vegetação, usando um so1o LVa de textura média e o trigo (Triticum aestivum) como planta teste, FEITOSA et alii (1977), determinaram a eficiência relativa de quinze (15) fontes de fosfatos nas doses de: 0, 100,200 e 400 $\mathrm{kg}$ de $\mathrm{P}_{2} \mathrm{O}_{5}$ total/ha. O fosfato de Catalão não diferiu da testemu nha: Resultado idêntico foi obtido por ALMEIDA NETo et alii (não publicado) utilizando um solo LRd e o Panicum mileacêึ (painço) como planta teste.

Um ensaio de campo e citado no Relatörio Anual da EMBRAPA-CPAC (1976a p.) num LVE textura argilosa, plantado com trigo sem_irrigação. Na dose de $800 \mathrm{~kg}$ de $\mathrm{P}_{2} \mathrm{O}_{5}$ total/ha, obteve-se uma eficiência relativa de $7 \%$ para o fosfato de Catalão, contra $1 \%$ para a testemunha em relação ao superfosfato triplo.

Outros trabalhos de campo competindo varias fontes de fósforo, estão sendo executados pela Empresa Goiana de Pesquisa gropecuária, com a cultura da soja. Os resultados preliminares obtidos com o fosfato de Catalão, têm mostrado efeitos preliminares não significativos em relação à testemunha (Informações do Arquivo da Empresa). 
4.1 - Considerações gerais

o experimento de campo foi instalado em dois locais: Goiānia e Santa Helena (GO).

o delineamento experimental foi, para o primeiro ano, o de blocos inteiramente casualizados, com cinco (5) tratamentos e quatro (4) repetições. Estes tratamentos consistiram da aplica ção do fosfato de Catalão a lanço com os seguintes niveis de $\mathrm{P}_{2}{ }_{5}$ total em $\mathrm{Kg} / \mathrm{ha}: \mathrm{L}_{0}=0, \mathrm{~L}_{1}=150, \mathrm{~L}_{2}=300, \mathrm{~L}_{3}=600 \mathrm{e} \mathrm{L}_{4}=$ 1200. A partir do segundo ano, as parcelas do ano anterior foram subdivididas em quatro subparcelas e adubadas no sulco com superfosfato triplo, cada uma recebendo, respectivamente as doses correspondentes a: $s_{0}=0, s_{1}=50, s_{2}=100$ e $s_{3}=200 \mathrm{~kg} / \mathrm{ha} \mathrm{de}$ $\mathrm{P}_{2} \mathrm{O}_{5}$ 
A utilização do superfosfato triplo como fonte de fósforo solúvel foi para eliminar a interferência de diferentes doses de outros elementos, principalmente do enxofre, como aconteceria no caso do superfosfato simples. No segundo ano o delineamento utilizado que foi o de blocos ao acaso com parcelas subdivididas nos permite verificar:

a) - o efeito residual do fosfato de Catalão pelos dados de produção da dose zero (0) de superfosfato triplo no sul co, nas diversas doses deste fosfato natural;

b) - o efeito das doses do superfosfato triplo através da ve rificação do tratamento de zero (0) $\mathrm{kg}$ de $\mathrm{P}_{2} \mathrm{O}_{5} / \mathrm{ha}$ do fosfato de Catalão a lanç;

c) - o efeito dos níveis de superfosfato triplo aplicados no sulco sobre os diferentes patamares do fosfato natural aplicado a lanço no ano anterior;

d) - comparando-se os itens a) e b) jä referidos, pode-se es tudar a competição dessas duas fontes de fósforo.

o tamanho das parcelas é de $256 \mathrm{~m}^{2}$ e o das subparcelas de $64 \mathrm{~m}^{2}(8 \mathrm{~m} \times 8 \mathrm{~m})$. A ärea ūtil e de $36 \mathrm{~m}^{2}(6 \mathrm{~m}$ X $6 \mathrm{~m})$, constituída de seis linhas de milho com $6,0 \mathrm{~m}$ de comprimento, espa çadas de 1,0 m entre linhas, tendo sido abandonada uma linha de cada lado e $1,0 \mathrm{~m}$ em cada extremidade. 
No primeiro ano, a produção em $\mathrm{kg}$ de milho/ha foi obti tida através da média aritmética das quatro subparcelas, uma vez que o delineamento era de blocos inteiramente casualizados.

A calagem foi feita antes do início de experimento com 2 te calcārio/ha, sendo o PRNT deste material igual a $76 \%$. Esta dosagem foi baseada, para o experimento de Goiânia, em sua anālise de solo de acordo com as recomendações de Fertilizantes para o Estado de Goiás, IV a aproximação (1976). Em Santa Helena, apezar de não haver necessidade desta dose, tomou-se a decisão de aplicä-1a para uniformização, sabendo-se que alguns dados de pesquisa mostram uma reação favorável ao calcário na produção, mesmo quando se aplicam fosfatos naturais, como o trabalho de GOEPFERT (1974) trabalhando com soja no Estado do Rio Grande do Sul. No Relatōrio Técnico Anual do CPAC (1976a), trabalhando num solo de cerrado (IVE) de Brasilia, com Brachiaria decumbens não foi encon trado um efeito significativo na produção, mas não houve diferença de produção entre a presença ou ausência de calcário.

Aplicou-se a seguir o fosfato de Catalão a lanço, incorporando-o com gradagens.

O cultivar de milho utilizado foi o HMD 1974 , bem pro dutivo nas competições regionais. Seu plantio foi em sulco de 15 a $20 \mathrm{~cm}$ de profundidade, colocando-se cerca de 10 sementes por metro linear, para posteriormente, com a altura de $15-20 \mathrm{~cm}$ ser desbastado para 5 plantas por metro linear. 
A adubação básica aplicada no sulco foi feita em todos os tratamentos e constou dos elementos $N$, K e $Z n$. 0 nitrogênio aplicado no plantio na dosagem de $20 \mathrm{~kg}$ de $\mathrm{N} / \mathrm{ha}$; o potäsio $100 \mathrm{Kg}$ de $\mathrm{K}_{2} 0 / \mathrm{ha}$ na forma de cloreto e zinco $10 \mathrm{Kg}$ de sulfato de zinco/ha. A adubação em cobertura foi feita aos 45 dias na base de $40 \mathrm{Kg}$ de $\mathrm{N} / \mathrm{ha}$. No primeiro ano a fonte do adubo nitrogenado foi a uréia e no segundo ano utilizou-se o sulfato de amonio, além de se ter aumentado a dosagem de sulfato de zinco para $20 \mathrm{~kg} / \mathrm{ha}$. Utilizou-se no início do primeiro ano uma adubação foliar generalizada de sulfato de zinco a $0,2 \%$.

No segundo ano foi introduzido nas subparcelas os diferentes niveis de superfosfato triplo jämencionados.

Os fosfatos utilizados foram os encontrados comercial mente com as características do QUADRO 1 e 2 .

QUADRO 1 - Granulometria do Fosfato de Catalão

\begin{tabular}{lccccc}
\hline PENEIRAS (mesh) & 60 & $60-100$ & $100-150$ & $150-200$ & 200 \\
\hline $\begin{array}{c}\% \text { do fosfato do } \\
\text { Catalão }\end{array}$ & $2,0 \%$ & $9,0 \%$ & $12, \%$ & $15,8 \%$ & $61,2 \%$ \\
\hline
\end{tabular}

A colheita dos grãos de milho foi feita manualmente, debulhada e pesada com a umidade de 15,5 a $16,0 \%$. 
Quadro 2 - Análise química dos adubos fosfatados (*)

\begin{tabular}{|c|c|c|c|c|}
\hline $\mathrm{P}_{2} \mathrm{O}_{5}$ & total & $\begin{array}{c}\mathrm{P}_{2} \mathrm{O}_{5} \text { solúvel em } \\
\text { ac. citrico a } 2 \% \\
(1: 100)\end{array}$ & $\mathrm{CaO}$ & Umidade \\
\hline Fosf。Catalão & $38,2 \%$ & $3,1 \%$ & $41,2 \%$ & $0,04 \%$ \\
\hline S.F. Triplo & $46,2 \%$ & n. det. & n. det. & n. det. \\
\hline
\end{tabular}

4.2 - Experimento de Goiânia

Foi localizado na Unidade Experimental de Goiânia (UE PAE-1) da Empresa Goiana de Pesquisa Agropecuária。

o solo era virgem revistido por um cerrado de vegetação média, formado em pastagem mesclada dos capins gordura e jara guá. Foi classificado pela equipe de Pedologia da secretaria da Agricultura de Goiás e mapeado como um solo de horizonte B 1atossôlico, Latossolo Vermelho Escuro, distrófico, de textura argilosa, com substrato de Gnaiss, epipedon ochrico, horizonte diagnós tico oxico-typic acrustox e unidade Uruana.

A anālise feita em 1975 pelo Laboratório da Secretaria da Agricultura de Goiás segundo os padrões da Rêde Nacional

$(*)$ - Anālise feita pela Secretaria da Agricultura de São Paulo a travēs da CATI. 
dos Laboratórios de Solo, deu o seguinte resultado: $\mathrm{pH}=5,4$; $\mathrm{AI}^{+++}=0,5$ e.mg/100 $\mathrm{cm}^{3}$ de terra $\mathrm{Ca}^{++}+\mathrm{Mg}^{++}=1,7 \mathrm{e} \cdot \mathrm{mg} / 100$ $\mathrm{cm}^{3}$ de terra; $\mathrm{P}=1 \mathrm{ppm}$ e $\mathrm{K}=42 \mathrm{ppm}$.

\section{3 - Experimento de Santa Helena}

Localizado próximo a esta cidade do sudoeste goiano, na área experimental alugada pela Emprêsa Goiana de Pesquisa Agro pecuāria.

O histórico desta área é pouco conhecido: sabe-se que era revestida por cerradão, jā plantada anteriormente, tendo recebido calagem e adubações completas.

o solo é classificado como um latossolo roxo distrófico, de textura argilosa.

A anāise química deste solo nos deu o resultado: $\mathrm{pH}=5,7 ; \mathrm{Al}^{+++}=0,1$ e. $\mathrm{mg} / 100 \mathrm{~cm}^{3}$ de terra; $\mathrm{Ca}^{+++} \mathrm{Mg}^{++}=$ $3,2 \mathrm{e} \mathrm{mg} / 100 \mathrm{~cm}^{3}$ de terra $\mathrm{P}=8 \mathrm{ppm}$ e $\mathrm{K}^{+}=115 \mathrm{ppm}$. 
Os resultados obtidos estão em função da produção de grãos de milho, expressa em kg/ha, dos experimentos realizados em Goiânia e Santa Helena com tipos de solos diferentes e com a dura ção preliminar de dois anos.

5.1 - Resultados do primeiro ano

A produção é apresentada na Tabela $3, \quad$ correspondente aos dois locais. 
TABELA 3 - Produção média de milho com as adubações de F.C. al a lanço no primeiro ano, em Goiânia e Santa Helena

\begin{tabular}{ccccc}
\hline Tratamentos & $\begin{array}{r}\text { Fosfato de Catalão } \\
\mathrm{kg} \mathrm{P}_{2}{ }^{2} / \text { ha. }\end{array}$ & $\begin{array}{c}\text { Produção de Milho } \\
\text { Goiânia (LVE) }\end{array}$ & Sta. Helena (LR) \\
\hline $\mathrm{L}_{0}$ & 0 & $1.656 \mathrm{~ns}$ & $1.918 \mathrm{~ns}$ \\
$\mathrm{~L}_{1}$ & 150 & $1.717 \mathrm{~ns}$ & $1.910 \mathrm{~ns}$ \\
$\mathrm{~L}_{2}$ & 300 & $1.667 \mathrm{~ns}$ & $1.693 \mathrm{~ns}$ \\
$\mathrm{~L}_{3}$ & 600 & $1.708 \mathrm{~ns}$ & $1.766 \mathrm{~ns}$ \\
$\mathrm{~L}_{4}$ & 1.200 & $2.114 \mathrm{~ns}$ & $1.719 \mathrm{~ns}$ \\
\hline DMS Tukey a 5\% & & 0.472 & 0.593 \\
\hline C. V. Res . F. C. & & $11.8 \%$ & $14.6 \%$ \\
\hline
\end{tabular}

a/ F.C. significa Fosfato de Catalão 
A anālise estatística de Goiânia pelo teste F a $5 \%$ mostrou-se significativa para os tratamentos das parcelas (Tabe1a 10), enquanto que em Santa Helena não houve significância (Tabela 11).

Em Goiânia e Santa Helena, no desdobramento das mëdias de produção nos diversos tratamentos conforme se apresenta nesta tabela, não houve diferença significativa entre as doses do F.C. aplicadas a lanço, pelo teste Tuckey a $5 \%$. Observa-se entre tanto que em Goiânia houve uma tendência crescente da produção no tratamento $\mathrm{L}_{4}$. Este fato não foi observado em Santa Helena.

Estas pequenas diferenças não significativas de prodụ ção com este fosfato, estão de acordo com os dados obtidos pela EMBRAPA-CPAC (1976), por FEITOSA et ali (1977) e por ALMEIDA NETo et $a$ lii (não publicado).

A baixa reação deste fosfato na produção, pode ser em consequência das hipótese aventadas a seguir:

a) - baixo teor solüvel do fosfato natural em ácido cítrico a 2\% (1:100) conforme pode-se verificar na Tabela 2 .

b) - modo de aplicação a lanço com baixa quantidade de P so1ūve1.

c) - moagem grosseira, como se pode observar na Tabela 1 .

A importância do grau de finura na solubilidade pode ser visto no trabalho de CATANI e NASCIMENTO $(1954)$. 
d) - presença de um ácido graxo denominado "tall oil", que envolvendo os grãos de fosfato impediria sua solubiliza ção e consequentemente o seu aproveitamento imediato pé la planta. Esse "tall oil" é usado no processo de concentração do material, na fase de flotação (informação pessoal de ARAUJO, P.L.).

\section{2. - Resultados do segundo ano}

A análise estatística será apresentada separadamente nos experimentos de Goiânia e Santa Helena.

Na discussão dos resultados, levou-se em conta a anāilse estatistica pelo teste Tuckey, ao nível de $5 \%$.

\subsection{1 - Experimento de Goiânia}

Os dados de produção podem ser analizados nas tabelas 4 e 5 respectivamente.

A anālise estatistica encontra-se na Tabela 12

e nos mostra que pelo teste F, hä uma resposta altamente significativa para os tratamentos com o F.C. e S.F.T. Entretanto não houve interação entre os tratamentos das parcelas e das subparce1 as . 
TABELA 4 - Produção média de milho aproveitando o efeito residual do F. C. no segundo ano em Goiânia e Sta. Helena

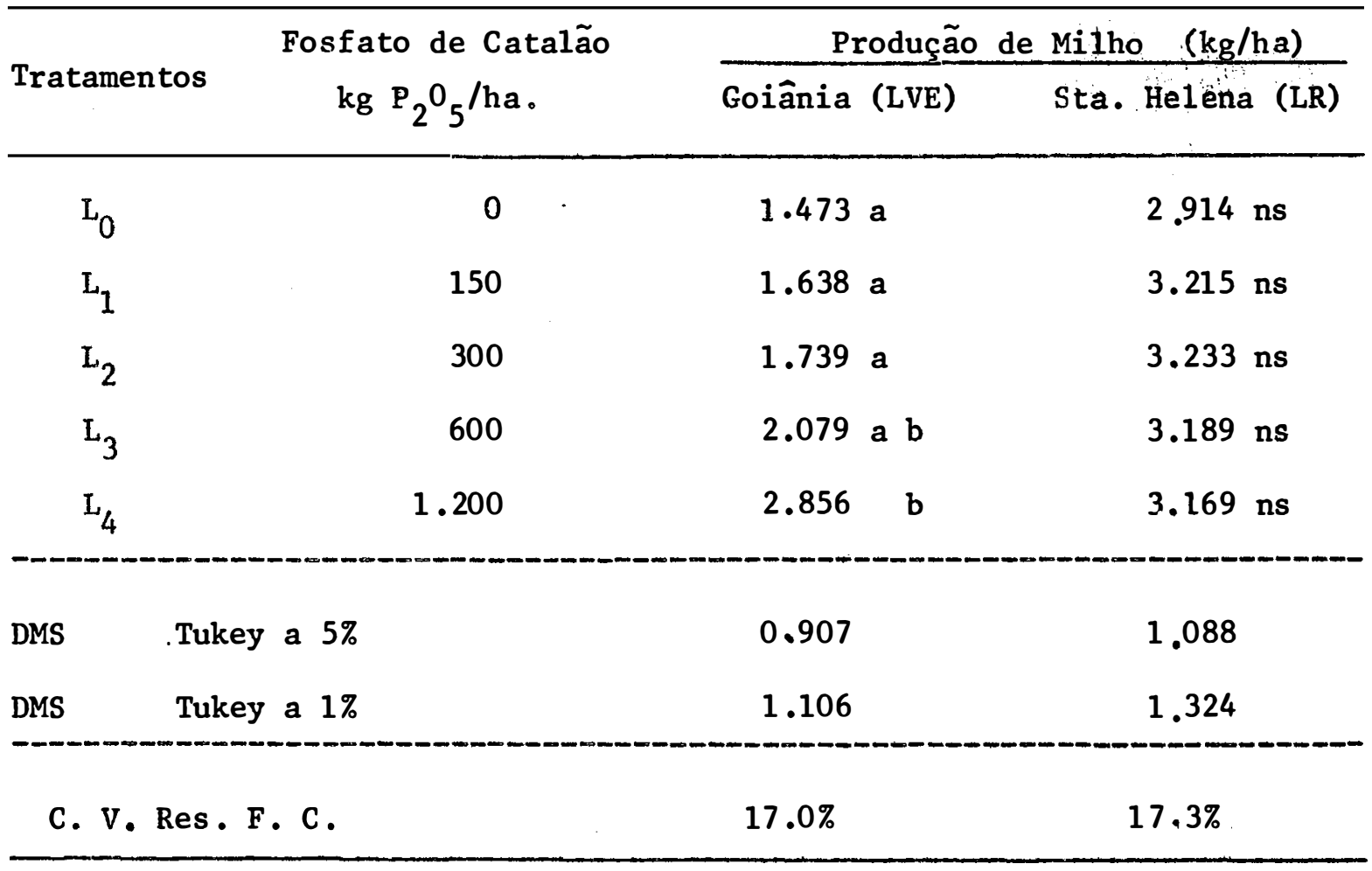

F. C. = Fosfato de Catalão 
TABELA 5 - Produção média de milho em $\mathrm{kg} / \mathrm{ha}$ em função das adubações fosfatadas no segundo ano, em Goiânia (LVE) al b/

\begin{tabular}{|c|c|c|c|c|c|c|c|c|c|}
\hline \multirow{2}{*}{$\begin{array}{l}\text { Trata- } \\
\text { mentos }\end{array}$} & \multirow{2}{*}{$\begin{array}{l}\text { Resīduo } \\
\text { F.C. } \\
\text { Lanço } \\
\text { kg/ha }\end{array}$} & \multirow[t]{2}{*}{ SFT } & Trat & E。 $s_{0}$ & & \multicolumn{2}{|l|}{$s_{1}$} & $s_{2}$ & $s_{3}$ \\
\hline & & & $\mathrm{P}_{2} \mathrm{O}_{5}^{\mathrm{kg} / \mathrm{ha}}$ & 0 & & 50 & & 100 & 200 \\
\hline & & & \multicolumn{7}{|c|}{$\mathrm{kg}$ de milho/ha } \\
\hline $\mathrm{L}_{0}$ & 0 & & & $\begin{array}{c}1.473 \\
(4)\end{array}$ & $a$ & $\begin{array}{c}2.854 \\
(3)\end{array}$ & $\mathbf{a}$ & $\begin{array}{l}3.332 \text { a } \\
(3)(2)\end{array}$ & $\begin{array}{c}4.766 \\
\text { (1) }\end{array}$ \\
\hline $\mathrm{L}_{1}$ & 150 & & & $\begin{array}{l}1.638 \\
(4)\end{array}$ & $a$ & $\begin{array}{c}3.202 \\
(3)\end{array}$ & a & $\begin{array}{l}3.604 \mathrm{a} \mathrm{b} \\
(3)(2)\end{array}$ & $\begin{array}{c}4.888 a \\
(1)\end{array}$ \\
\hline $\mathrm{L}_{2}$ & 300 & & & $\begin{array}{l}1.739 \\
(4)\end{array}$ & $a$ & $\begin{array}{c}3 \cdot 336 \\
(3)\end{array}$ & $a b$ & $\begin{array}{c}4.096 \mathrm{a} \mathrm{b} \\
(2)\end{array}$ & $\begin{array}{c}4.853 a \\
(1)\end{array}$ \\
\hline $\mathrm{L}_{3}$ & 600 & & & $\begin{array}{c}2.079 \\
(3)\end{array}$ & $a b$ & $\begin{array}{l}4: 054 \\
(2)\end{array}$ & $a b$ & $\begin{array}{l}4.501 \\
(2)(1)\end{array}$ & $\begin{array}{c}5.038= \\
(1)\end{array}$ \\
\hline $\mathrm{L}_{4}$ & 1.200 & & & $\begin{array}{c}2.856 \\
(3)\end{array}$ & b & $\begin{array}{l}2.877 \\
(2)\end{array}$ & b & $\begin{array}{l}4.446 \quad b \\
(2)(1)\end{array}$ & $\begin{array}{l}5,167 \text { a } \\
\text { (1) }\end{array}$ \\
\hline
\end{tabular}

Catalão dentro S. F. T.

T. Tukey DMS a $5 \%=0.907$ DMS a $1 \%=1,106$
S. F. T. dentro de Catalão

T. Tuckey DMS a $5 \%=0.718$ DMS a $1 \%=0.888$

C. V.res.F. C. $=17.04 \%$

C. V. res. S.F.T. $=10.59 \%$

a/ as letras são utilizadas para comparar as médias nas colunas;

b/ os números são utilizados para comparar as médias nas linhas. Quando iguais não diferem estatisticamente. 
No desdobramento, observa-se pelo teste $F$ que houve uma resposta altamente significativa para todos os tratamentos das parcelas dentro das subparcelas. A anālise dos tratamentos das subparcelas dentro da parcela deu altamente significativo, menos para a combinação $\mathrm{L}_{4} \mathrm{~S}_{3}$.

Aplicando-se o teste Tuckey a $5 \%$ para verificar se houve ou não significância na produção de milho, do efeito do S.F.T. dentro dos tratamentos com o F.C., pode-se observar nas Tabelas 4 e 5 respectivamente.

Pode-se representar simbolicamente está anālise da seguinte forma: al

$$
\begin{aligned}
& \mathrm{L}_{4} s_{0}=\mathrm{L}_{3} \mathrm{~s}_{0} \\
& \mathrm{~L}_{3} \mathrm{~s}_{0}=\mathrm{L}_{2} \mathrm{~s}_{0}=\mathrm{L}_{1} \mathrm{~s}_{0}=\mathrm{L}_{0} \mathrm{~s}_{0} \\
& \mathrm{~L}_{4} \mathrm{~s}_{0}>\mathrm{L}_{2} \mathrm{~s}_{0}=\mathrm{L}_{1} \mathrm{~s}_{0}=\mathrm{L}_{0} \mathrm{~s}_{0}
\end{aligned}
$$

Estes dados fornecem o efeito residual do F.C. aplicado no ano an terior. Estão de acordo com BRAGA (1970) que afirma que os fosfa to naturais só reagem quando aplicados em altas doses, justifican do assim o fracasso do fosfato natural em alguns experimentos com doses baixas, principalmente quando se compara fontes pelo seu teor total de $\mathrm{P}_{2} \mathrm{O}_{5}$

Analizando os níveis da S.F.T. no sulco dentro do efeito residual do Catalão (Tabela 5), ver-se-a agora o tratamento no sulco $\left(S_{1}\right)$ nos värios tratamentos do F.C.:

\footnotetext{
al

= representa que não houve diferença estatĩstica ao nĩvel de $5 \%$. $>$ significa que hā diferença estatisstica ao nível de $5 \%$, sendo que o vértice representa a produção menor.
} 


$$
\begin{aligned}
& \mathrm{L}_{4} \mathrm{~s}_{1}=\mathrm{L}_{3} \mathrm{~s}_{1}=\mathrm{L}_{2} \mathrm{~s}_{1} \\
& \mathrm{~L}_{3} \mathrm{~s}_{1}=\mathrm{L}_{2} \mathrm{~s}_{1}=\mathrm{L}_{1} \mathrm{~s}_{1}=\mathrm{L}_{0} \mathrm{~s}_{0} \\
& \mathrm{~L}_{4} \mathrm{~s}_{1}>\mathrm{L}_{1} \mathrm{~s}_{1}=\mathrm{L}_{0} \mathrm{~s}_{1}
\end{aligned}
$$

Verificando o nível de $100 \mathrm{~kg}$ de $\mathrm{P}_{2} \mathrm{O}_{5} / \mathrm{ha}$ de S.F.T. $\left(s_{2}\right)$ aplicado ao sulco tem-se:

$$
\begin{aligned}
& \mathrm{L}_{4} \mathrm{~s}_{2}=\mathrm{L}_{3} \mathrm{~s}_{2}=\mathrm{L}_{2} \mathrm{~s}_{2}=\mathrm{L}_{1} \mathrm{~s}_{2} \\
& \mathrm{~L}_{2} \mathrm{~s}_{2}=\mathrm{L}_{1} \mathrm{~s}_{2}=\mathrm{L}_{0} \mathrm{~s}_{2} \\
& \mathrm{~L}_{4} \mathrm{~s}_{2}=\mathrm{L}_{3} \mathrm{~s}_{2}>\mathrm{L}_{0} \mathrm{~s}_{2}
\end{aligned}
$$

Ao nivel de $200 \mathrm{~kg}$ de $\mathrm{P}_{2} \mathrm{O}_{5} / \mathrm{ha}$ de S.F.T $\left(s_{3}\right)$ aplicado no sulco tem-se:

$$
\mathrm{L}_{4} \mathrm{~s}_{3}=\mathrm{L}_{3} \mathrm{~s}_{3}=\mathrm{L}_{2} \mathrm{~s}_{3}=\mathrm{L}_{1} \mathrm{~s}_{3}=\mathrm{L}_{0} \mathrm{~s}_{3}
$$

Aqui não houve diferença estatística significativa neste nível de adubação no sulco, pois neste solo o efeito da dose alta no sulco praticamente mascarou o efeito do F.C.

A anälise das doses de S.F.T. dentro das doses do F.C. é abordado a seguir (Tabela 5 e 7).

Quando a dose do F.C. é de zero $\mathrm{Kg} \mathrm{P}_{2} \mathrm{O}_{5} / \mathrm{ha}$ isolase o efeito do S.F.T. e tem-se:

$$
\begin{aligned}
& \mathrm{I}_{0} \mathrm{~s}_{3}>\mathrm{L}_{0} \mathrm{~s}_{2}=\mathrm{L}_{0} \mathrm{~s}_{1}=\mathrm{L}_{0} \mathrm{~s}_{0} \\
& \mathrm{~L}_{0} \mathrm{~s}_{2}=\mathrm{L}_{0} \mathrm{~s}_{1}>\mathrm{L}_{0} \mathrm{~s}_{0}
\end{aligned}
$$

Analisando-se os tratamentos com S.F.T. sobre o nivel de $150 \mathrm{~kg} \mathrm{P}{ }_{2}{ }_{5} / \mathrm{ha}$ do F.C.:

$$
\begin{aligned}
& \mathrm{L}_{1} \mathrm{~s}_{3}>\mathrm{L}_{1} \mathrm{~s}_{2}=\mathrm{L}_{1} \mathrm{~s}_{1}=\mathrm{L}_{1} \mathrm{~s}_{0} \\
& \mathrm{~L}_{1} \mathrm{~s}_{2}=\mathrm{L}_{1} \mathrm{~s}_{1}>\mathrm{L}_{1} \mathrm{~s}_{0}
\end{aligned}
$$


A ordem de produção dos tratamentos no sulco do S. F.T. sobre o nível de $300 \mathrm{~kg} \mathrm{P}_{2} \mathrm{O}_{5} / \mathrm{ha}$ do F.C. é a segunte:

$$
\mathrm{L}_{2} \mathrm{~s}_{3} \times \mathrm{L}_{2} \mathrm{~s}_{2}>\mathrm{L}_{2} \mathrm{~s}_{1}>\mathrm{L}_{2} \mathrm{~s}_{0}
$$

Sobre o nível de $600 \mathrm{~kg} \mathrm{P}_{2} \mathrm{O}_{5} / \mathrm{ha}$ do F.C. o comportą mento foi:

$$
\begin{aligned}
& \mathrm{L}_{3} \mathrm{~s}_{3}=\mathrm{L}_{3} \mathrm{~s}_{2} \\
& \mathrm{~L}_{3} \mathrm{~s}_{2}=\mathrm{L}_{3} \mathrm{~s}_{1}>\mathrm{L}_{3} \mathrm{~s}_{0} \\
& \mathrm{~L}_{3} \mathrm{~s}_{3}>\mathrm{L}_{3} \mathrm{~s}_{1}>\mathrm{L}_{3} \mathrm{~s}_{0} \\
& \text { Sobre o nivel de } 1.200 \mathrm{~kg} \mathrm{P}{ }_{2} \mathrm{O}_{5} / \mathrm{ha} \text { do F.C. tem-se: } \\
& \mathrm{L}_{4} \mathrm{~s}_{3}=\mathrm{L}_{4} \mathrm{~s}_{2} \\
& \mathrm{~L}_{4} \mathrm{~s}_{2}=\mathrm{L}_{4} \mathrm{~s}_{1}>\mathrm{L}_{4} \mathrm{~s}_{0} \\
& \mathrm{~L}_{4} \mathrm{~s}_{3}>\mathrm{L}_{4} \mathrm{~s}_{1}>\mathrm{L}_{4} \mathrm{~s}_{0}
\end{aligned}
$$

\subsection{2 - Experimento de Santa Helena}

Os dados de produção podem ser analizados através das Tabelas 4 e 6 , apresentadas respectivamente.

Pelo teste F dado na tabela 13 , verifica se um resultado altamente significativo para os tratamentos na subparcela (S.F.T.), enquanto que os tratamentos da parcela (F.C.) não houve significância. Também não houve interação entre os tratamentos das parcelas e das subparcelas.

No desdobramento dos tratamentos no teste $F$ do efe to do S.F.T. dentro do efeito do F.C., os tratamentos $\mathrm{L}_{0}$ e $\mathrm{L}_{2}$ 
foram altamente significativos (1\%), enquanto que os tratamentos $\mathrm{L}_{4}, \mathrm{~L}_{3}$ e $\mathrm{L}_{1}$ foram significativos a $5 \%$. 0 efeito do F.C. dentro dos tratamentos de S.F.T não foram significativos.

Aplicando-se o teste Tukey para verificar a análise do efeito de S.F.T dentro dos tratamentos como F.C., que podem ser vistos nas Tabela 4 e 6 , observa-se que não houve res posta significativa a nenhuma dose do efeito rasidual do F.C. Portanto neste tipo de solo este fosfato natural não está reagindo. Entretanto nota-se uma pequena diferença não significativa entre os tratamentos que receberam o Catalão e os que não o receberam, o que não aconteceu no primeiro ano da aplicação.

Nos outros tratamentos do S.F.T. dentro dos tratamentos do F.C., que se pode ver na Tabela 6 , constatou-se que para nehum deles houve efeitos significativos.

\section{Analisando os tratamentos da subparcela (S.F.T.)}

sobre o tratamento $\mathrm{L}_{0}$ (F.C.) tem-se o efeito isolado do S.F.T. (Tabela 6 e 7), que se pode representar por:

$$
\begin{aligned}
& \mathrm{L}_{0} s_{3}=\mathrm{L}_{0} s_{2}=\mathrm{L}_{0} s_{1} \\
& \mathrm{~L}_{0} s_{1}=\mathrm{L}_{0} s_{0} \\
& \mathrm{~L}_{0} s_{3}=\mathrm{L}_{0} s_{2}>\mathrm{L}_{0} s_{0}
\end{aligned}
$$

Com a dose fixa do efeito residual do F.C. no nível $150 \mathrm{~kg} \mathrm{P}{ }_{2} \mathrm{O}_{5} / \mathrm{ha}\left(\mathrm{L}_{1}\right)$ tem-se:

$$
\begin{aligned}
& \mathrm{L}_{1} \mathrm{~s}_{3}=\mathrm{L}_{1} \mathrm{~s}_{2}=\mathrm{L}_{1} \mathrm{~s}_{1} \\
& \mathrm{~L}_{1} \mathrm{~s}_{1}=\mathrm{L}_{1} \mathrm{~s}_{0} \\
& \mathrm{~L}_{1} \mathrm{~s}_{3}=\mathrm{L}_{1} \mathrm{~s}_{2}>\mathrm{L}_{1} \mathrm{~s}_{0}
\end{aligned}
$$


TABELA 6 - Produção média de milho em $\mathrm{kg} / \mathrm{ha}$ em função das adubações fosfatadas no segundo ano em Santa Helena (L.R.)

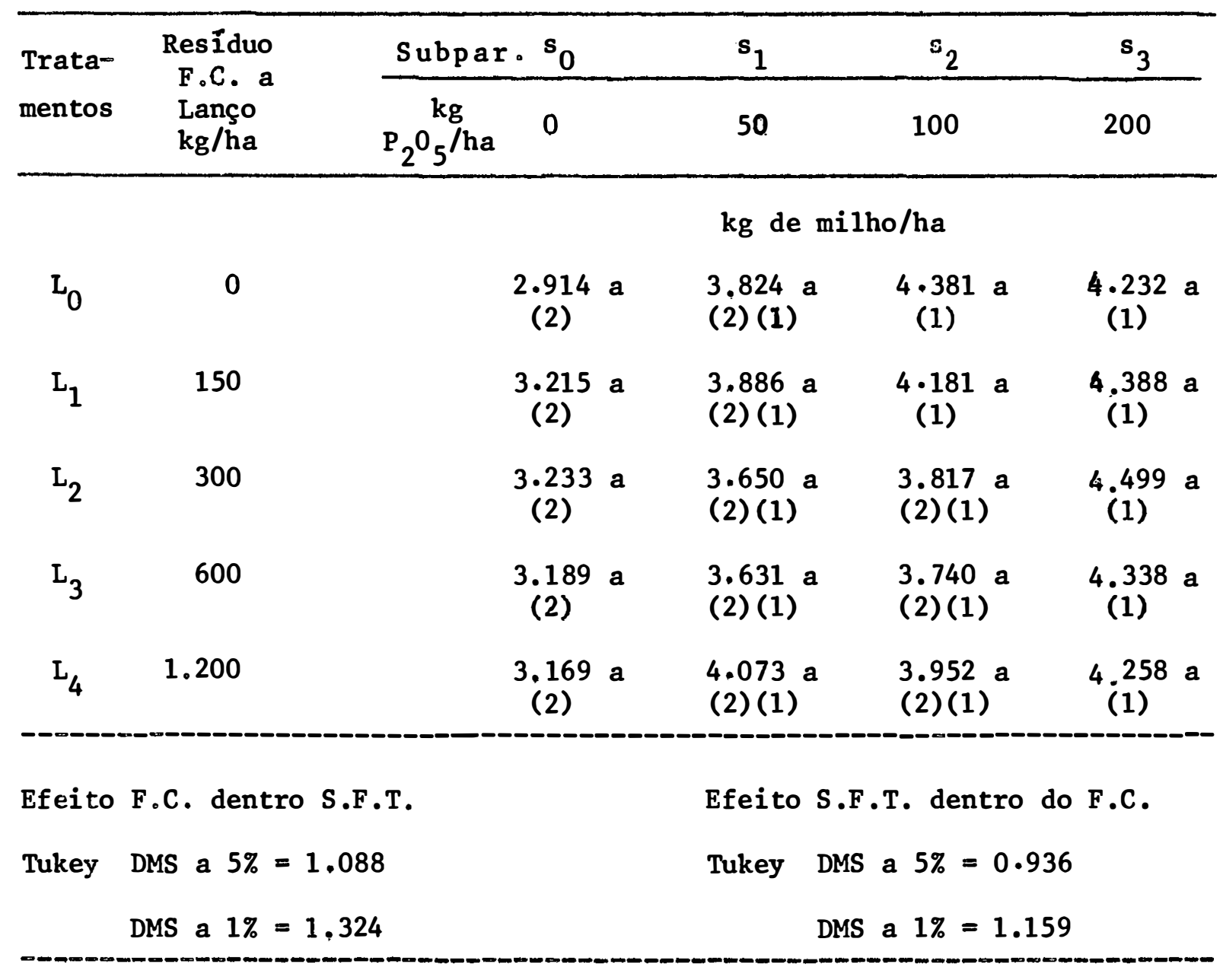

C. V. res. F. C. $=17.33 \%$

C. V. res. S.F.T. $=12.95 \%$

as letras são utilizadas para comparar as médias nas colunas:

os números são utilizados para comparar as médias nas linhas. Quando iguais não diferem estatisticamente. 
TABEla 7 - Produção média de milho em função das adubações fosfatadas nas localidades de Goiânia e Sta. Helena em dois anos agrí colas.

\begin{tabular}{|c|c|c|c|c|c|c|}
\hline \multirow{3}{*}{$\begin{array}{l}\text { F.C. kg } \\
\mathrm{P}_{2} \mathrm{O}_{5} / \mathrm{ha} \\
\text { (1 anço) }\end{array}$} & \multirow{2}{*}{\multicolumn{2}{|c|}{$\begin{array}{c}\text { Produção de grãos } \\
(\mathrm{kg} / \mathrm{ha})\end{array}$}} & \multicolumn{4}{|c|}{$\begin{array}{l}29 \text { ANO - Efeito conjunto do resid. } \\
\text { F.C. com O S.F.T. }\end{array}$} \\
\hline & & & \multirow{2}{*}{$\begin{array}{l}\begin{array}{l}\text { Doses } \\
\text { tos }\end{array} \\
\text { F.C. } \\
(1 \text { anço) }\end{array}$} & \multirow{2}{*}{$\begin{array}{r}\begin{array}{r}\text { dos fosfa- } \\
\left(\mathrm{kg} \mathrm{P}_{2} \mathrm{O}_{5}\right)\end{array} \\
\text { S.F.T. } \\
(\text { sulco) }\end{array}$} & \multicolumn{2}{|c|}{$\begin{array}{l}\text { Produção de grãos } \\
(\mathrm{kg} / \mathrm{ha})\end{array}$} \\
\hline & $\begin{array}{l}\text { Gujania } \\
\text { I.V.E. }\end{array}$ & $\begin{array}{c}\text { sta.Helena } \\
\text { L.R. }\end{array}$ & & & $\begin{array}{c}\text { Goiânia } \\
\text { L.V.E. }\end{array}$ & $\begin{array}{c}\text { Sta.Helena } \\
\text { L.R. } \\
\end{array}$ \\
\hline 0 & 1,656 & 1,918 & $0+$ & $\begin{array}{r}0 \\
50 \\
100 \\
200\end{array}$ & $\begin{array}{l}1,473 \\
2,854 \\
3,332 \\
4,766\end{array}$ & $\begin{array}{l}2,914 \\
3,824 \\
4,381 \\
4,232\end{array}$ \\
\hline 150 & 1,717 & 1,910 & $150+$ & $\begin{array}{r}0 \\
50 \\
100 \\
200\end{array}$ & $\begin{array}{l}1,638 \\
3,202 \\
3,604 \\
4,888\end{array}$ & $\begin{array}{l}3,215 \\
3,886 \\
4,181 \\
4,388\end{array}$ \\
\hline 300 & 1,666 & 1,693 & $300+$ & $\begin{array}{r}0 \\
50 \\
100 \\
200\end{array}$ & $\begin{array}{l}1,739 \\
3,336 \\
4,096 \\
4,853\end{array}$ & $\begin{array}{l}3,233 \\
3,650 \\
3,817 \\
4,499\end{array}$ \\
\hline 600 & 1,709 & 1,766 & $600+$ & $\begin{array}{r}0 \\
50 \\
100 \\
200\end{array}$ & $\begin{array}{l}2,079 \\
4,054 \\
4,501 \\
5,038\end{array}$ & $\begin{array}{l}3,189 \\
3,631 \\
3,740 \\
4,338\end{array}$ \\
\hline 1.200 & 2,114 & 1,719 & $1.200+$ & $\begin{array}{r}0 \\
50 \\
100 \\
200\end{array}$ & $\begin{array}{l}2,856 \\
3,877 \\
4,446 \\
5,167\end{array}$ & $\begin{array}{l}3,169 \\
4,073 \\
3,952 \\
4,258\end{array}$ \\
\hline
\end{tabular}


$\mathrm{Na}$ dose fixa de $300 \mathrm{~kg}$ de $\mathrm{P}_{2} \mathrm{O}_{5} / \mathrm{ha}$ do F.C. o efeito dos tratamentos de S.F.T.:

$$
\begin{aligned}
& \mathrm{L}_{2} \mathrm{~s}_{3}=\mathrm{L}_{2} \mathrm{~s}_{2}=\mathrm{I}_{2} \mathrm{~s}_{1} \\
& \mathrm{~L}_{2} \mathrm{~s}_{2}=\mathrm{L}_{2} \mathrm{~s}_{1}=\mathrm{L}_{2} \mathrm{~s}_{0} \\
& \mathrm{~L}_{2} \mathrm{~s}_{3}>\mathrm{L}_{2} \mathrm{~s}_{0}
\end{aligned}
$$

Com $600 \mathrm{~kg}$ de $\mathrm{P}_{2}{ }^{\mathrm{O}} 5 / \mathrm{ha}$ do F.C. tem-se os seguintes efeitos do S.F.T.

$$
\begin{aligned}
& \mathrm{L}_{3} \mathrm{~s}_{3}=\mathrm{L}_{3} \mathrm{~s}_{2}=\mathrm{L}_{3} \mathrm{~s}_{1} \\
& \mathrm{~L}_{3} \mathrm{~s}_{2}=\mathrm{L}_{3} \mathrm{~s}_{1}=\mathrm{L}_{3} \mathrm{~s}_{0} \\
& \mathrm{~L}_{3} \mathrm{~s}_{3}>\mathrm{L}_{3} \mathrm{~s}_{0}
\end{aligned}
$$

$$
\text { No nível fixo de } 1.200 \mathrm{~kg} \text { de } \mathrm{P}_{2} \mathrm{O}_{5} / \mathrm{ha} \text { os efeitos do }
$$

S.F.T. são:

$$
\begin{aligned}
& \mathrm{L}_{4} \mathrm{~s}_{3}=\mathrm{L}_{4} \mathrm{~s}_{2}=\mathrm{L}_{4} \mathrm{~s}_{1} \\
& \mathrm{~L}_{4} \mathrm{~s}_{2}=\mathrm{L}_{4} \mathrm{~s}_{1}=\mathrm{L}_{4} \mathrm{~s}_{0} \\
& \mathrm{~L}_{4} \mathrm{~s}_{3}>\mathrm{L}_{4} \mathrm{~s}_{0}
\end{aligned}
$$

\section{3 - Considerações finais}

$$
\text { Com a Tabela } 7 \text { tem-se uma visão conjunta }
$$

das produções obtidas nos dois experimentos.

Verifica-se no primeiro ano que não houve efeito do fosfato de Catalão em ambas localidades.

No segundo ano este fosfato reagiu significativamen te somente em Goiania e nas doses mais altas. Neste local o so 10 apresenta uma composição química inferior, principalmente no 
que se refere ao teor de fósforo. Neste ano, em ambas localidades foi o emprego do S.F.T. que provocou os maiores aumentos de produção. A figura 1 permite a comparação do efeito das duas fontes de fósforo em Goiânia e permite estimar que 1.200 $\mathrm{Kg}$ de $\mathrm{P}_{2}{ }^{0}{ }_{5}$ total do F.C. equivale em termos de produção à dose de $50 \mathrm{Kg} / \mathrm{ha}$ na forma de S.F.T.

Para as duas localidades não houve interação entre os tratamentos das parcelas e subparcelas.

Em Goiânia e Santa Helena o efeito do S.F.T. dentro dos tratamentos do F.C. foram significativos e variou quanto as doses da fonte solúvel.

Analizando em Goiânia o efeito do F.C. dentro do S.F.T. houve significância, mas tal fato não aconteceu em Santa Helena, o que indica que em solo melhor o efeito do Catalão praticamente desaparece.

Observou-se que as maiores produções dos experimentos deram-se com as maiores doses de fósforo no solo de Goiânia, que é considerado como pior em produção quando não se utiliza adubações. Fato semelhante foi observado por ALMEIDA NETo (1975) quando comparou três tipos de solos do cerrado e também nos dados obtidos por HOEFLICH et a $i$ i (1976), comparando-se dois tipos de cerrado quanto aos sistemas de exploração econômica.

Como sugestões para melhorar e tornar mais comple to o experimento em si, aproveitando este delineamento que é bas- 


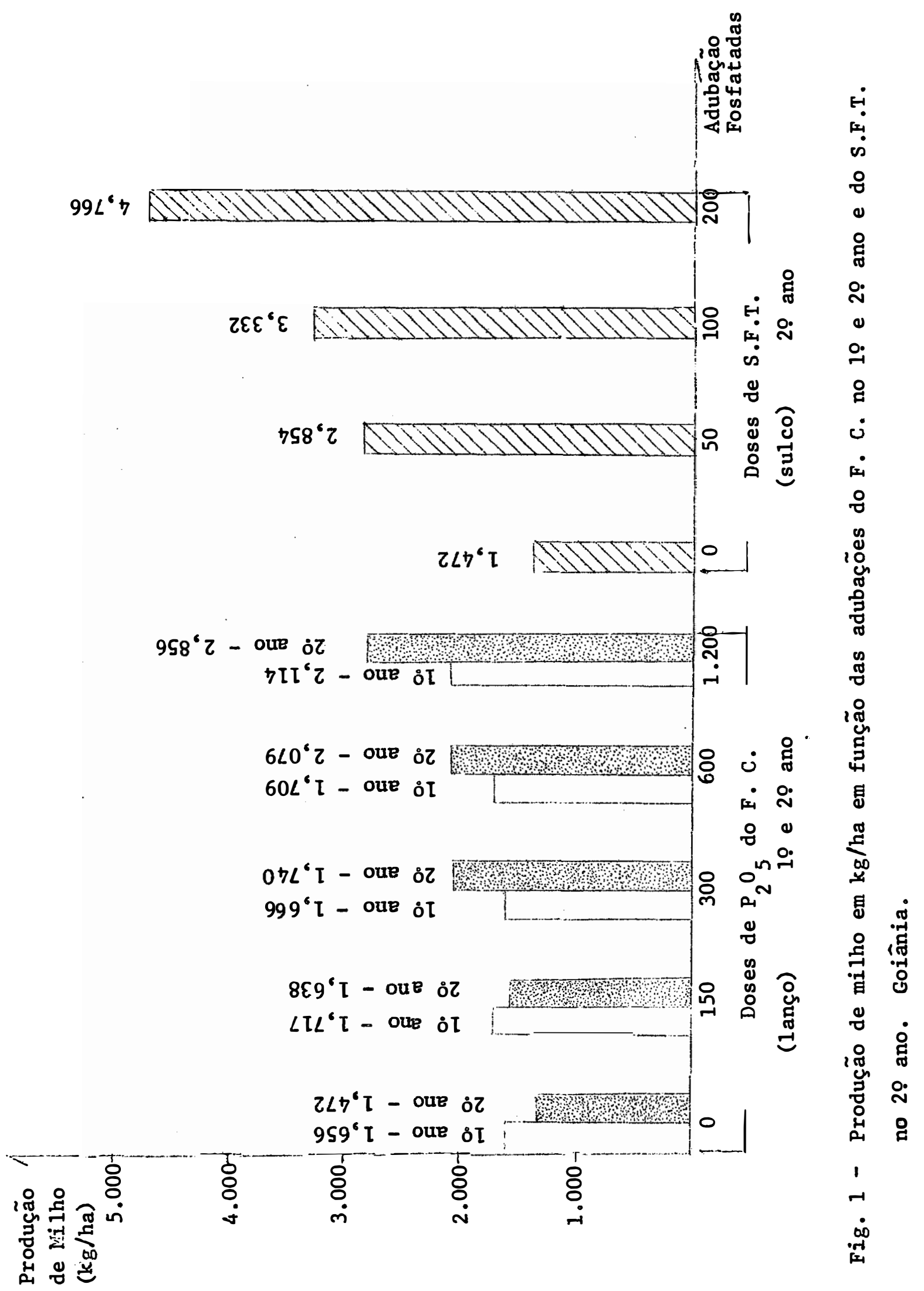


tante interessante com respeito às informações fornecidas, podese sugerir em futuros trabalhos que se acrescente pelo menos mais três níveis de S.F.T. aplicados a lanço, para se verificar seu efeito residual. Elevar as doses do F.C. para que se eleve a quantidade do fósforo solúvel para as plantas. Lançar o experimento em outros tipos de solos. Deve-se obter maiores informações, tais como, analises físicas e químicas do solo. A anālise química feita anualmente acompanhando o teor de fósforo com diferentes tipos de extratores. A adubação foliar da cultura deve ser tambẻm feita.

Paralelamente, outros experimentos como o estudo econômico das combinações das värias doses e fontes, não se esquecendo de computar o transporte em determinadas distâncias das fontes produtoras e consumidoras, que hoje representa um grande ônus (ETM $1977 d$ ).

Para estes tipos de experimentos, deve-se prever uma duração maior pois resultados de dois anos são dados preliminares e que pode com o passar do tempo serem modificados.

Alêm deste tipo de experimento, pode-se citar outros trabalhos testados em diferentes locais e fontes, para tentar melhorar a solubilização do fosfato de Catalão. Podemos destacar:

a) - o estudo de sua granulometria.

b) - Trabalho com a oxidação microbiológica do enxof́re que conforme trabalho de NELLER (1960) que acrescentou o S 
nos fosfatos naturais e o trabalho de SWABY (s.d.) que estudou a biossolubilização do fosfato com o S e bactérias sulfúricas com relativo sucesso. Em ensaio de vasos no Brasil, OLIVEIRA et alii (1977) obtiveram bons resultados.

c) - Estudos com o aquecimento e calcinação dos fosfatos de rocha estão em andamento e com bons resultados conforme citam ROBERTS e WHITE (1974) e STEPHENS e LIPSETT (1973) .

d) - G'RBUCHEV (1974) tratando da acidulação parcial dos fosfatos de rocha com o äcido orto-fosfórico diz que ela é importante para aumentar seu efeito residual e evi tar sua fixação com os óxidos de ferro e alumínio. Ele obteve resultados iguais ou superiores ao superfosfato triplo. Efeito semelhante na cultura do milho foi obti do por LUTZ (1971).

e) - o plantio de leguminosas ou outras plantas boas extrato ras de fósforo, poderia ser tentada, na solubilização dos fosfatos com o seu posterior aproveitamento pela in corporação das mesmas. 
Nos dois anos de experimentação com dois tipos de solos (LVE e LR) sob vegetação de cerrado, pode-se concluir que:

a) - a natureza do solo exerce influência importante na resposta do milho aos adubos fosfatados;

b) - no primeiro ano não houve efeito significativo do fosfa to de Catalão; no segundo ano houve efeito significati vo apenas em Goiânia, nas doses mais elevadas;

c) - houve um efeito marcante do superfosfato triplo na pro dução, o que indica a necessidade da aplicação de uma fonte solúvel de $P$ ao menos nos primeiros anos de explo ração dos dois "cerrados". 
41.

7 - SUMMARY

Two experiments were conducted in suils under "cerrado" vegetation which are representative of those presently used for agricultural purpases. These experiments were located in the vicinity of Goiania (Red-Yellow Latosol) and Santa Helena (Roxo Latosol) municipalities of the State of Goiaz, Brazil. "Catalão" natural phosphate was broadcasted in the first year at the rates of $0,150,300,600$ and $1,200 \mathrm{Kg}$ of total $\mathrm{P}_{2} \mathrm{O}_{5} / \mathrm{ha}$. This rockphosphate is an apatic cuntaining $38.2 \%$ of total $\mathrm{P}_{2}{ }_{5}$ and $3.1 \%$ soluble in $2 \%$ citric acid $(1: 100)$. In the second year a second application was made by banding on the side with triple superphos 
phate at the rates of $0,50,100$ and $200 \mathrm{~kg}$ of $\mathrm{P}_{2} \mathrm{O}_{5} / \mathrm{ha}$. This second application was made on the plots that previously received equivalent dosages of $\mathrm{P}_{2}{ }{ }_{5}$ as rock phosphate.

No significant response in the yield of corn (Zea mays, L.) in the two sites was observed in the first year as a result of applying "catalão" phosphate. A significant response was re corded in Goiania in the second year. In Santa Helena no significant response was observed for "Catalão" natural phosphate. Triple superphosphate had a pronunced effect on yield, indicating that an application of a soluble form of phosphate is necessary in the first year of cultivation on these two types of "cerrado soils". 
ALMEIDA NETO, J.X. de, 1975. Fixação de fosfatos em solos de "cer rado" de Goiās. Piracicaba, ESALQ/USP, 90 p (Tese de Mestrado).

ALMEIDA NETO, J.X. de, L.C.VALIADARES e Y. de CARVALho, (não pu blicado). Efeito do "Bat-Guano" na solubilização de alguns fosfatos naturais Goiânia.

BRAGA, J.M., 1970. Resultados Experimentais com o uso de Fosfato de Araxā e Outras Fontes de Fósforo: revisão de literatura. Viçosa, UFV, 61 p. (Serie técnica. Boletim 21). 
BRAGA, J.M. e J. YAHNER, 1968a. Estudo comparativo de fosfato de de Araxă e superfosfato simples em cultura do milho, em um so so de Viçosa, Minas Gerais. Experientiae, Viçosa, 8: 143-163.

BRAGA, J.M. e J. YAHNER, 1968b. Estudo de correlação de anālise química do solo e da planta em cultura de milho. Experientiae, Viçosa, 8 (5): 164-195.

BRASIL. Leis, Decretos, etc. 1974. Programa Nacional de Fertilizantes e Calcário Agrícola. Diário Oficial, Brasília, 12 nov. Secção 1, Parte 1, p.12857-12874.

CALDWELL, A. C., A. HUSTRULID e F.L. HAMMERS, 1956. Residual availability in the soil of various sources of phosphate as measured by plant absorption of $\mathrm{P}^{32}$ and by soil test Proceedin gs of the Soil Science Socienty, of Amercida, Madison, 20 (1): 25-28.

CAMPBELL, R.E., 1965. Phosphorus fertilizer residual effects on irrigated crops in rotation. Proceedings of the Soil Science Society, of Amercia, Madison, 29 (1):67-70.

CAMPOS, H. de e PIMENTEL GOMES, F., 1976. O comportamento das in terações de efeitos lineares nos grupos de ensaios fatoriais de adubação de milho. In: 9ä Reunião Brasileira de milho e Sorgo, Piracicaba, SP, ESALQ, P 321-326.

CARvalho, P. de, A.F. da EIRA e D. PEllegrino, 1969. Solubilização quantitativa de fosfatos insolúveis, por algumas espécies dos gêneros Aspergizlus e Penicillium. Anais da Escola Superior de Agricultura Luiz de Queiroz, Piracicaba, 26: 173-185.

CARvalHo, W.T. de, 1974a. Aspectos geológicos e petrogrä́icos do complexo ultramäfico-alcalino de Catalão I, Go. In: 280 Congresso Brasileiro de Geologia, Pôrto Alegre, p. 107-123. 
CARVALHO, W.T. de, 1974b. Recursos minerais do complexo ultramá fico-alcalino de Catalão I, Go. In: 280 Congresso Brasile ro de Geologia, Pôrto Alegre, p. 165-184.

CARVALHO, W.T. de e P.L. ARAUJO, 1974. Perspectivas de aprovei tamento econômico dos depósitos minerais associados ao complexo ultramáfico-alcalino de Catalão I, GO. In: 289 Congresso Brasileiro de Geologia, Porto Alegre, p. 131-141.

CATANI, R.A., 1970. A solubilidade de fosfatos naturais em 8o1 ução de ácido cítrico a 2\%, na proporção de 1.200 . Anais. da Escola Superior de Agricultura Luiz de Queiroz, Piracica ba, 27: $1-14$.

CATANI, R.A. e A.C. NASCIMENTO, 1952. Solubilidade de alguns fosfatos naturais. Revista de Agricultura, Piracicaba. 27: $141-168$.

CATANI, R.A. e A.C. NASCIMENTO, 1954. Influencia do grau de fi nura na solubilidade de fosfatos naturais. Revista de Agri cultura, Piracicaba, 29 (1-2): 5-14.

CATANI, R.A., A.C. NASCIMENTO e N.A. COSTA, 1956. Fertilizantes fosfatados, classificação e interpretação dos resultados analiticos. In: $4^{a}$ Reunião Brasileira de Ciência do Solo, Rio de Janeiro, p. 49-64.

CATANI, R.A. E D. PELLEGRINO, 1960. Solubilidade de fosfatos naturais em solução de ácido cítrico a 2\%. Modificação nas condições de agitação. Anais da Escola Superior de Agricul. tura Luiz de Queiroz, Piracicaba, 17: 247-254. 
CATANI, R.A. e N.A. GLORIA, 1961. A disponibilidade do fósforo de diversos fosfatos estudados por meio do método de Neubaner. Anais da Escola Superior de Agricultura Luiz de Queiroz, Piracicaba, 18: 193-204.

COMISSÃO ESTADUAL DE FERTILIDADE DO SOLO (s.d.). Recomendações.

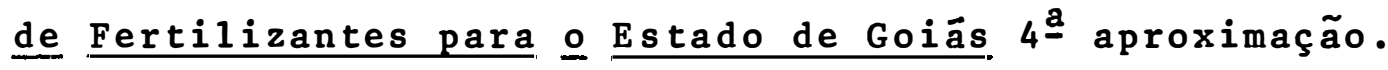

DOLL, E.C.; MILLER e J.F. FREEMAN, 1960. Initial and residual effects of rock_phosphate and superfosfate. Agronomy. Jour Na1, Madison, 52 (5): 247-250. Superphosphate.

EIM-ENGENHARIA PARA A INDUSTRIA MINERAL S.A., 1977a. Rochas fosfáticas no Brasil e no Mundo: Geologia, mineração e beneficiamento dos fosfatos brasileiros. In: 10 Curso sobre Fosfatos Brasileiros, São Paulo.

EIM-ENGENHARIA PARA A INDUSTRIA MINERAL S.A., 1977b. Comportados fosfatos brasileiros na produção de ācido fosfórico e fertilizantes. In: 19 Curso sobre Fosfatos Brasileiros, São Paulo.

EIM-ENGENHARIA PARA A INDUSTRIA MINERAL S.A. 1977c. Produção de superfosfato simples e triplo com rochas nacionais - Estudos de laboratório. In: 10 Curso sobre Fosfatos Brasileiros, São Paulo.

EIM-ENGENHARIA PARA A INDUSTRIA MINERAL S.A., 1977d。 Disbribuição de fertilizantes e matērias primas. In: 1o Curso so bre Fosfatos Brasileiros, são Paulo.

EMBRAPA - Centro Nacional de Pesquiza Arroz e Feijão, 1975. In ventārio Tecnológico do Arroz 1975. Goiânia. 342 p. 
EMBRAPA. Centro de Pesquisa Agropecuāria dos Cerrados, 1976 . Relatório técnico anual. Brasīlia. 150 p.

EMBRAPA. Departamento de Informação e Documentação, 1976 . Cer rado: Bibliografia Analítica. Brasília, 361 p.

ENSMINGER, L.E. e R.W. PEARSON, 1957. Residual effects of various phosphates as measured by yields, $\mathrm{P}^{32}$ uptake, and ex tractable phosphorus. Proceedings of the soil science society of Amer., Madison, 21 (1): 80-84.

FEITOSA, C.T., B. van RAIJ, A.R. DECHEN e J.C. ALCARDE, 1977 . Determinação preliminar da eficiência relativa dos fosfatos em casa de Vegetação. In: 160 Congresso Brasileiro de ciên cia do solo, são Luiz, $\overline{M A}$.

FREITAS, F。G. de e C.0. SILVEIRA, 1976. Principais solos sob vegetação de cerrado e sua aptidão agrícola. In: IV Simpósio sobre o Cerrado, Brasília, p. 155-194.

GOEPFERT, C.F., 1974. Fosfato natural, uma alternativa para re dução no custo da adubação. IPAGRo Informa, Porto Alegre, 10: 8-9.

GOIĀS. Secretária da Agricultura, 1975. Plano de Ação: ano agrícola $1975 / 76$. Goiania. 100 p.

G'RBUCHEV, I., 1974. Effectiveness of concentrated and certain underacidulated superphosphates. Pochvoznanie $\underline{i}$ Agrokhimiya, 9 (5): 56-54. Apud Soils. and Fertilizers, Harpendan, 38 (9): 294,1975 .

KAMPRATH, E.J., 1967. Residual effect of large aplications of phosphorus on hight phosphorus fixing soils. Agronomy Jour nal, Madison, 59 (1): 25-27. 
HOEFLICH, V.A., E.R. CRUZ, J. PEREIRA, F.F. DUQUE e H. TOLLINI, 1976. Sistema de produção agrícola no cerrado. In: 49 Sim pósio sobre o Cerrado, Brasília, p. 37-58.

LUTZ JR., J.A., 1971. Comparison of partiall acidulated roch phosphate and concentrated superphosphate as sources of $\underline{P}$ for corn. Agronomy Journal, Madison, 63 (6): 919-922.

MALAVOLTA E., 1977. O fósforo na agricultura brasileira. In: 10 Curso sobre Fosfatos Brasileiros, São Paulo.

MANOILOVIC, S. e M. ZERAVICA, 1976. The efficiency of waterand-citrate soluble $P$ of complex fertilizers on chernozem and other soils. Apud. Int. Fert. Congress, Moscow, 3: 106-114. Apud Phosphorus in Agriculture, Paris, 31 (71): $32,1977$.

MELL), F. de A.F. de M.O. do BRASIL SOBRINHO, S. JOLY e E. MALA VOLTA, 1974. Efeito residual de superfosfato, fosfato precipitado e fosforita de 01 inda em cana de açúcar. Anais da Escola Superior de Agricultura Luiz de Queiroz, Piracicaba, 31: 243-249.

MOSCHLER, W.W., R.D. KREBS, e S.S . OBENSHAIM, S.S ., 1957. Avai lability of residual phosphorus from long-time rock phosphate and superphosphate applications to Groselose silt loam. Proceedings of the Soil Science Society of America, Madison, 21 (3): 293-295.

NELLER, J.R., 1960. Inter relations of sulphur and phosphorus for fertilizing grass-1and. In: 8 the International Grass 1- and Congress England, p. 90-93. 
NOGUEIRA, S.S.S., O.C. BATAGLIA e H.A.A. MASCARENHAS, 1977. Efeitos de fontes e doses de fósforo sobre a área foliar e pro dução de grãos de soja. Bragantia Campinas, 36 (unico): XXVII .

OLIVEIRA, M.L.C., E.S. LOPES, M.T.R. da SILVA e V. NAGAI, 1977 Influência da oxidação microbiológica do S na solubilização da apatita de Apatita de Araxá. Revista Brasileira de Ciência do Solo, Campinas, 1 (1): 24 .

OLSEN, R.S., 1953. Inorganic phosphorus in alkaline and calcareous soils. In: PIERRE, W.H e NORMAN, V., eds. Soil and Fertilizer Phosphorus in Crop Nutrition, New York, Academic Press, p. 89-118.

PARADA, J.M. e S.M. de ANDRADE, 1976. Cerrados: Recursos Minerais. Zn: 49 Simpósio sobre o Cerrado, Brasília, p. 195-209.

REID, R.L. e G.A. JUNG, 1974. Effects of elements other than nitrogen on the nutritive value of forage $\mathrm{Zn}$ : Forrage $\mathrm{p}$. 395-435 In: MAYS, D.A. et alii, ads. Forage Fertilizacion. Madison, Am. Soc. of Agronomy, p. 395-435.

ROBERTS, O.T. e M.S. WHITE, 1974. Some factors affecting agrono mic response to apatites and to calcined Christmas Insland iron aluminon phosphates. New Zeland Journal Agricultural Research, Welligton 17: (479-484).

SHELTON, J.E. e N.T. COLEMAN, 1968. Inorganic phosphorus fractions and their relationship to residual value of large application of phosphorus on hight phosphorus fixing soils. Pro ceedings of the Soil science Society, of America, Madison, 32

SMITH, C.M. e J.T. PESEK, 1962. Camparing measurements of the effect of residual fertilizer phosphorus in some Iowa soils. Procedings of the Soil Science Society of America, Madison, 26 (6): 563-566. 
SOARES, W.V. E. LOBATO, E. GONZALES e G.C. NADERMAN JUNIOR, 1975. Liming soils of the Brasilian cerrado. $\mathrm{Zn}_{\mathrm{n}}$ BORNEMISZA, E.E.A. ALAVARADo, ed. Soil Management in Tropical America. Raleigh, N.C., North Carolina State University, p. 283299 .

STELLY, M. e H.D. MORRIS, H.D., 1953. Residual effect of phosphorus on cotton grown on Cecil soil a determined with radioactive phosphorus. Procedings of the. Soil. Science of America Madison 17 (3): 267-269.

STEPHENS, A. e L. LIPSETT, 1973. Calcined grade roch phosphate from Christmas Island as a source of $P$ for pastures in Southern Australia. Austr. CSIRO, Div. Plant. Ind, Field Sta. Rec. 12 ( 2$): 43-53$.

SWABY, R.J. (s.d.) Biological Superphosphate Biosuper. Adelaide, CSIRO, Division of Soils. 
51.

9 - A P E N D I C E 
TABELA 8 - Dados de produção de grãos de milho ( $\mathrm{kg} / \mathrm{ha}$ no primeiro ano. (1975/1976)

\begin{tabular}{|c|c|c|c|c|}
\hline \multirow{2}{*}{$\begin{array}{l}\text { Nỉveis de } \\
\text { fosfato } \\
\text { Cataläo } \\
\text { a Lanço }\end{array}$} & \multicolumn{2}{|c|}{ Repetição I } & \multicolumn{2}{|c|}{ Repetição II } \\
\hline & Goiânia & Santa Helena & Goiânia & Santa Helena \\
\hline 0 & $\begin{array}{l}1.836 \\
1.011 \\
1.275 \\
1.450\end{array}$ & $\begin{array}{r}1.185 \\
946 \\
1.683 \\
1.106\end{array}$ & $\begin{array}{l}1.197 \\
2.158 \\
1.367 \\
1.667\end{array}$ & $\begin{array}{l}2.135 \\
1.664 \\
2.056 \\
1.354\end{array}$ \\
\hline Mëdia & 1.393 & 1.230 & 1.597 & 1803 \\
\hline 1 & $\begin{array}{l}1.331 \\
1.297 \\
1.006 \\
1.361\end{array}$ & $\begin{array}{l}1.590 \\
1.928 \\
1.286 \\
1.463\end{array}$ & $\begin{array}{l}1.061 \\
1.539 \\
3.111 \\
1.172\end{array}$ & $\begin{array}{l}2.038 \\
1.735 \\
1.700 \\
2.206\end{array}$ \\
\hline Média & 1.249 & 1.567 & 1.721 & 1.920 \\
\hline 2 & $\begin{array}{r}1.728 \\
1.447 \\
1.631 \\
839\end{array}$ & $\begin{array}{r}1.160 \\
975 \\
1.517 \\
1.203\end{array}$ & $\begin{array}{l}1.492 \\
1.445 \\
1.639 \\
1.728\end{array}$ & $\begin{array}{r}1.057 \\
928 \\
1.296 \\
1.068\end{array}$ \\
\hline Média & 1.411 & 1.214 & 1.576 & 1.087 \\
\hline 3 & $\begin{array}{l}1.450 \\
1.425 \\
1.542 \\
1.008\end{array}$ & $\begin{array}{r}825 \\
1.178 \\
1.183 \\
593\end{array}$ & $\begin{array}{l}1.592 \\
1.869 \\
1.633 \\
1.517\end{array}$ & $\begin{array}{l}1.256 \\
1.533 \\
1.167 \\
1.490\end{array}$ \\
\hline Média & 1.356 & 945 & 1.653 & 1.362 \\
\hline 4 & $\begin{array}{l}2.478 \\
2.100 \\
2.589 \\
1.872\end{array}$ & $\begin{array}{r}1.335 \\
875 \\
856 \\
881\end{array}$ & $\begin{array}{l}1.983 \\
1.914 \\
1.936 \\
1.975\end{array}$ & $\begin{array}{l}1.622 \\
1.765 \\
1.188 \\
2.097\end{array}$ \\
\hline Média & 2.260 & 987 & 1.952 & 1.668 \\
\hline
\end{tabular}


TABELA 8 - Continuação

\begin{tabular}{|c|c|c|c|c|}
\hline \multirow{2}{*}{$\begin{array}{l}\text { Níveis de } \\
\text { fosfato } \\
\text { Catalão } \\
\text { a Lanço }\end{array}$} & \multicolumn{2}{|c|}{ Repetição III } & \multicolumn{2}{|c|}{ Repetição IV } \\
\hline & Goiânia & Santa Helena & Goiânia & Santa Helena \\
\hline 0 & $\begin{array}{l}2.236 \\
1.708 \\
2.442 \\
1.925\end{array}$ & $\begin{array}{l}1.575 \\
1.619 \\
2.199 \\
2.018\end{array}$ & $\begin{array}{l}1.533 \\
1.336 \\
1.806 \\
1.556\end{array}$ & $\begin{array}{l}2.957 \\
2.339 \\
2.508 \\
3.335\end{array}$ \\
\hline Média & 2.078 & 1.853 & 1.558 & 2.785 \\
\hline 1 & $\begin{array}{l}2.653 \\
2.033 \\
1.392 \\
1.006\end{array}$ & $\begin{array}{l}2.339 \\
1.776 \\
1.789 \\
1.257\end{array}$ & $\begin{array}{l}2.075 \\
2.728 \\
1.700 \\
2.006\end{array}$ & $\begin{array}{l}2.511 \\
2.107 \\
3.053 \\
1.778\end{array}$ \\
\hline Média & 1.771 & 1.790 & 2.127 & 2.362 \\
\hline 2 & $\begin{array}{l}1.825 \\
1.647 \\
1.650 \\
1.700\end{array}$ & $\begin{array}{l}1.449 \\
1.654 \\
2.676 \\
1.683\end{array}$ & $\begin{array}{l}2.089 \\
2.089 \\
1.978 \\
1.739\end{array}$ & $\begin{array}{l}2.739 \\
2.164 \\
2.406 \\
3.064\end{array}$ \\
\hline Média & 1.706 & 1.878 & 1.974 & 2.593 \\
\hline 3 & $\begin{array}{l}2.008 \\
1.917 \\
1.817 \\
2.057\end{array}$ & $\begin{array}{l}1.863 \\
2.447 \\
2.540 \\
1.818\end{array}$ & $\begin{array}{l}1.928 \\
1.533 \\
2.625 \\
1.422\end{array}$ & $\begin{array}{l}2.085 \\
3.056 \\
2.224 \\
2.997\end{array}$ \\
\hline Média & 1.947 & 2.167 & 1.877 & 2.591 \\
\hline 4 & $\begin{array}{l}2.011 \\
2.369 \\
2.117 \\
1.897\end{array}$ & $\begin{array}{l}1.929 \\
1.967 \\
2.075 \\
2.126\end{array}$ & $\begin{array}{l}2.325 \\
2.017 \\
2.172 \\
2.069\end{array}$ & $\begin{array}{l}2.207 \\
2.417 \\
2.482 \\
1.676\end{array}$ \\
\hline Média & 2.099 & 2.024 & 2.146 & 2.196 \\
\hline
\end{tabular}


TABELA 9 - Dados de produção de grãos de milho (kg/ha) :10 segundo ano $(1976 / 1977)$

\begin{tabular}{|c|c|c|c|c|c|}
\hline \multirow{4}{*}{$\begin{array}{l}\text { Efeito } \\
\text { Residual } \\
\text { do Catalão } \\
\text { a Lanço * }\end{array}$} & \multirow{4}{*}{$\begin{array}{l}\text { Nível } \\
\text { S. F. } \\
\text { Triplo } \\
\text { (sulcr) }\end{array}$} & \multicolumn{4}{|c|}{$1976 / 1977$} \\
\hline & & \multicolumn{4}{|c|}{ Produção kg de Milho por ha } \\
\hline & & \multicolumn{2}{|c|}{ Repetição I } & \multicolumn{2}{|c|}{ Repetição II } \\
\hline & & Goiânia & Sta.Helena & Goiânia & Sta.Helena \\
\hline 0 & $\begin{array}{l}0 \\
1 \\
2 \\
3\end{array}$ & $\begin{array}{l}1.431 \\
2.889 \\
2.911 \\
4.911\end{array}$ & $\begin{array}{l}2.417 \\
3.500 \\
3.800 \\
3.390\end{array}$ & $\begin{array}{l}1.306 \\
3.244 \\
4.139 \\
4.792\end{array}$ & $\begin{array}{l}2.100 \\
3.139 \\
4.284 \\
4.033\end{array}$ \\
\hline 1 & $\begin{array}{l}0 \\
1 \\
2 \\
3\end{array}$ & $\begin{array}{l}1.139 \\
2.250 \\
2.835 \\
3.939\end{array}$ & $\begin{array}{l}2.492 \\
3.136 \\
3.186 \\
4.261\end{array}$ & $\begin{array}{l}1.778 \\
3.419 \\
3.856 \\
6.272\end{array}$ & $\begin{array}{l}2.838 \\
3.139 \\
3.806 \\
4.347\end{array}$ \\
\hline 2 & $\begin{array}{l}0 \\
1 \\
2 \\
3\end{array}$ & $\begin{array}{l}1.667 \\
2.611 \\
4.300 \\
5.256\end{array}$ & $\begin{array}{l}1.556 \\
3.078 \\
3.306 \\
4.147\end{array}$ & $\begin{array}{l}1.972 \\
3.394 \\
3.722 \\
5.211\end{array}$ & $\begin{array}{l}2.000 \\
3.139 \\
3.172 \\
3.843\end{array}$ \\
\hline 3 & $\begin{array}{l}0 \\
1 \\
2 \\
3\end{array}$ & $\begin{array}{l}1.944 \\
3.444 \\
4.197 \\
4.811\end{array}$ & $\begin{array}{l}2.442 \\
3.728 \\
3.922 \\
4.164\end{array}$ & $\begin{array}{l}2.581 \\
3.917 \\
4.583 \\
5.272\end{array}$ & $\begin{array}{l}2.390 \\
3.303 \\
3.575 \\
4.414\end{array}$ \\
\hline 4 & $\begin{array}{l}0 \\
1 \\
2 \\
3\end{array}$ & $\begin{array}{l}3.053 \\
3.647 \\
4.625 \\
5.319\end{array}$ & $\begin{array}{l}2.361 \\
3.778 \\
2.761 \\
4.164\end{array}$ & $\begin{array}{l}2.653 \\
4.097 \\
4.367 \\
5.319\end{array}$ & $\begin{array}{l}2.389 \\
3.825 \\
4.208 \\
4.050\end{array}$ \\
\hline
\end{tabular}


TABELA 9 - Continuação

\begin{tabular}{|c|c|c|c|c|c|}
\hline \multicolumn{2}{|c|}{ Tratamentos } & \multicolumn{4}{|c|}{$1976 / 1977$} \\
\hline \multirow{3}{*}{$\begin{array}{l}\text { Efeito } \\
\text { Residual } \\
\text { do Catalão } \\
\text { a Lanço }\end{array}$} & \multirow{3}{*}{$\begin{array}{l}\text { Nível } \\
\text { S. F. } \\
\text { Triplo } \\
\text { (Sulco) }\end{array}$} & \multicolumn{4}{|c|}{ Produção kg de Milho por ha } \\
\hline & & \multicolumn{2}{|c|}{ Repetição III } & \multicolumn{2}{|c|}{ Repetição IV } \\
\hline & & Goiânia & Sta.Helena & Goiânia & Sta.Helena \\
\hline 0 & $\begin{array}{l}0 \\
1 \\
2 \\
3\end{array}$ & $\begin{array}{l}2.278 \\
2.669 \\
2.861 \\
4.778\end{array}$ & $\begin{array}{l}3.478 \\
4.011 \\
4.736 \\
4.444\end{array}$ & $\begin{array}{r}875 \\
2.613 \\
3.417 \\
4.583\end{array}$ & $\begin{array}{l}3.661 \\
4.647 \\
4.704 \\
5.061\end{array}$ \\
\hline 1 & $\begin{array}{l}0 \\
1 \\
2 \\
3\end{array}$ & $\begin{array}{l}1.836 \\
3.361 \\
3.533 \\
4.283\end{array}$ & $\begin{array}{l}3.606 \\
4.092 \\
4.611 \\
4.114\end{array}$ & $\begin{array}{l}1.800 \\
3.778 \\
4.194 \\
5.058\end{array}$ & $\begin{array}{l}3.925 \\
5.178 \\
5.119 \\
4.832\end{array}$ \\
\hline 2 & $\begin{array}{l}0 \\
1 \\
2 \\
3\end{array}$ & $\begin{array}{l}1.583 \\
3.339 \\
3.867 \\
4.278\end{array}$ & $\begin{array}{l}4.667 \\
4.044 \\
4.311 \\
4.719\end{array}$ & $\begin{array}{l}1.736 \\
4.000 \\
4.494 \\
4.667\end{array}$ & $\begin{array}{l}4.708 \\
4.339 \\
4.478 \\
5.285\end{array}$ \\
\hline 3 & $\begin{array}{l}0 \\
1 \\
2 \\
3\end{array}$ & $\begin{array}{l}2.028 \\
4.356 \\
4.458 \\
5.333\end{array}$ & $\begin{array}{l}3.603 \\
3.789 \\
4.503 \\
3.658\end{array}$ & $\begin{array}{l}1.764 \\
4.500 \\
4.764 \\
4.736\end{array}$ & $\begin{array}{l}4.319 \\
3.703 \\
2.958 \\
5.114\end{array}$ \\
\hline 4 & $\begin{array}{l}0 \\
1 \\
2 \\
3\end{array}$ & $\begin{array}{l}2.411 \\
3.501 \\
3.931 \\
4.583\end{array}$ & $\begin{array}{l}4.286 \\
4.911 \\
5.003 \\
4.611\end{array}$ & $\begin{array}{l}3.306 \\
4.264 \\
4.861 \\
5.447\end{array}$ & $\begin{array}{l}3.639 \\
3.778 \\
3.836 \\
4.206\end{array}$ \\
\hline
\end{tabular}


TABELA 10 - Análise estatística do primeiro ano do experimento de Goiânia

$\begin{array}{crrr}\text { Dados transformados em } x=x+\sqrt{0.0000} & \\ 1,3930 & 1,5970 & 2,0780 & 1,5580 \\ 1,2490 & 1,7210 & 1,7710 & 2,1270 \\ 1,4110 & 1,5760 & 1,7060 & 1,9740 \\ 1,3560 & 1,6530 & 1,9470 & 1,8770 \\ 2,2600 & 1,9520 & 2,0990 & 2,1460\end{array}$

\begin{tabular}{crrrr}
\hline Causa de Variação & G. L. & S. Q. & Q. M. & F \\
\hline A & 4 & 0,5945 & 0,1486 & 3,3865 \\
B & 3 & 0,5547 & 0,1849 & $4,2127 *$ \\
R & 12 & 0,5266 & 0,0438 & \\
\hline Total & 19 & 1,6759 & & \\
\hline
\end{tabular}

Médias por Tratamentos

$\operatorname{MV}(5)=2,1142$

MV $(2)=1,7169$

$\operatorname{MV}(4)=1,7082$

$\operatorname{MV}(3)=1,6667$

MV $(1)=1,6564$
Médias por Blocos

MB $(4)=1,9363$

MB (3) $=1,9201$

$\mathrm{MB}(2)=1,6997$

$\mathrm{MB}(1)=1,5337$

Média Geral $=1,7725$

C. V. $=11,8192$

Tukey ao nível de 5\%
Trat.
$=0,4724$
Blocos
$=0,3935$ 
TABELA 11 - Análise estatística do primeiro ano do experimento de Santa Helena

Dados transformados em $x=x+\sqrt{0.0000}$

$\begin{array}{llll}1,2300 & 1,8030 & 1,8530 & 2,7850 \\ 1,5670 & 1,9200 & 1,7900 & 2,3620 \\ 1,2140 & 1,0870 & 1,8780 & 2,5930 \\ 0,9450 & 1,3620 & 2,1670 & 2,5910 \\ 0,9870 & 1,6680 & 2,0240 & 2,1960\end{array}$

\begin{tabular}{ccccr}
\hline Causa de Variação & G. L. & S. Q. & Q. M. & \multicolumn{1}{c}{ F } \\
\hline A & 4 & 0,1803 & 0,0450 & 0,6519 \\
B & 3 & 4,7274 & 1,5758 & $22,7825 * *$ \\
C & 12 & 0,8300 & 0,0691 & \\
\hline Total & 19 & 5,7378 & & \\
\hline
\end{tabular}

Médias por Tratamentos

$\operatorname{MV}(1)=1,9177$

MV (2) $=1,9097$

$\operatorname{MV}(4)=1,7662$

$\operatorname{MV}(5)=1,7187$

$\mathrm{MV}(3)=1,6929$

Média Geral $=1,8010$

C. v.

$=14,6021$

Tukey ao nível de 5\%

Trat.

$=0,5930$

Blocos

$$
=0,4939
$$

Médias por Blocos

$M B(4)=2,5053$

MB (3) $=1,9423$

$\mathrm{MB}(2)=1,5679$

$M B(1)=1,1885$ 
TABEL A 12 - Anālise estatística do segundo ano do experimento de Goiânia

\begin{tabular}{|c|c|c|c|c|}
\hline Causa de Variação & G. L • & S. Q. & Q. M. & F \\
\hline $\mathbf{R}$ & 3 & 2,6938 & 0,8979 & 2,4001 \\
\hline A & 4 & 10,5806 & 2,6451 & $7,0703 *$ \\
\hline RES A & 12 & 4,4894 & 0,3741 & \\
\hline PARC. & 19 & 17,7639 & & \\
\hline $\mathbf{R}$ & 3 & 93,5171 & 31,1723 & $215,8756 * *$ \\
\hline$A * B$ & 12 & 2,8022 & 0,2335 & 1,5172 \\
\hline R D A 1 & 3 & 22,1545 & 7,3848 & $51,1416 * *$ \\
\hline R D A 2 & 3 & 21,5243 & 7,1748 & $49,6869 * *$ \\
\hline R D A 3 & 3 & 21,2465 & 7,0821 & $49,0457 * *$ \\
\hline R D A 4 & 3 & 19,9731 & 6,6577 & $46,1060 * *$ \\
\hline R D A 5 & 3 & 11,4210 & 3,8070 & $26,3643 * *$ \\
\hline \multirow{2}{*}{\multicolumn{5}{|c|}{$\begin{array}{l}\text { Grau de } L \text { ỉberdade A D. B }=41 \\
\text { Quadrado Médio do Resíduo A D. } B=0,1009\end{array}$}} \\
\hline & & & & \\
\hline A D B 1 & 4 & 4,8254 & 1,2063 & $11,9541 * *$ \\
\hline A D B 2 & 4 & 3,9064 & 0,9766 & $9,6774 * *$ \\
\hline A D B 3 & 4 & 4,2446 & 1,0611 & $10,5152 * *$ \\
\hline Res 。B & 45 & 6,4980 & 0,1444 & 1,0073 \\
\hline Total & 79 & 120,5813 & & \\
\hline
\end{tabular}

Média Geral $=3,5899$

C.V. Res. A $=3,5899$

C.V. Res. B . = $=17,0378$

Diferenças mínimas significativas:

Ao nível de $5 \% \quad$ Ao nível de $1 \%$

$\begin{array}{llllll}\text { A } & 0,6896 & \text { Q }=4,5110 & \text { A } & 0,8930 & Q=5,8400 \\ \text { B } & 0,3209 & \text { Q }=3,7775 & \text { B } & 0,3972 & Q=4,6750 \\ \text { B } & 0,5744 & Q=4,2000 & \text { B } & 0,7522 & Q=5,5000 \\ \text { A * B } 1,0126 & \text { Q }=5,3300 & \text { A * B } & 1,1708 & Q=6,1625 \\ \text { A D B } 0,9068 & Q=4,0369 & \text { A D B } & 1,1061 & Q=4,9245 \\ \text { B J A } 0,7177 & Q=3,7775 & \text { B D A } & 0,8882 & \text { Q }=4,6750\end{array}$


TABELA 13 - Análise estatística segundo do experimento de Santa Helena

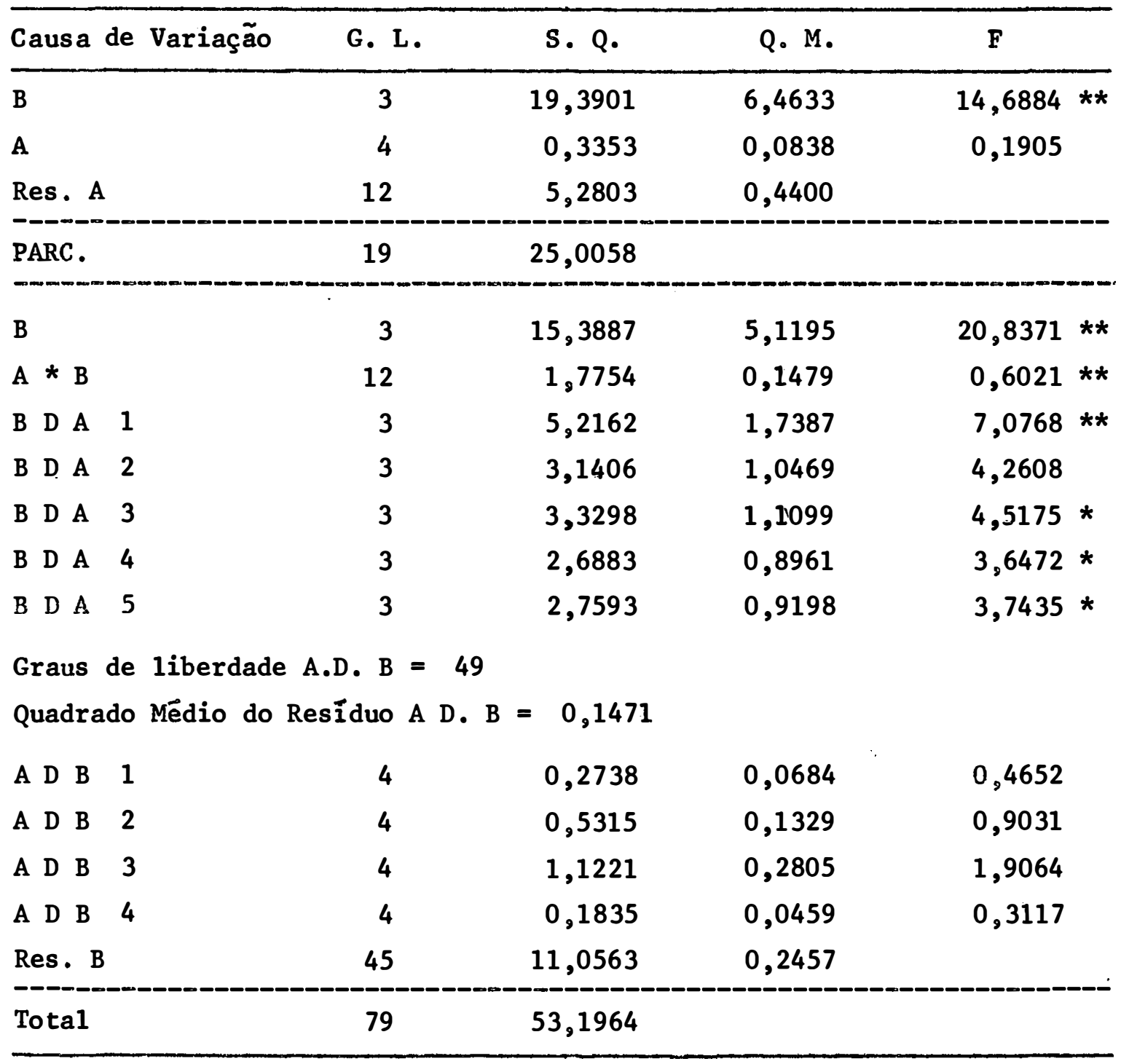

Me̊dia Geral $=3,8283$
C. V. Res. A
$=17,3271$
C. V. Res. B
$=12,9474$

Diferençæ mínimas significativas:

Ao nível de $5 \%$

$\begin{array}{llll}\text { A } & & 0,7479 & Q=4,5100 \\ \text { B } & & 0,4186 & Q=3,7775 \\ \text { B } & & 0,6229 & Q=4,2000 \\ \text { A * B } & 1,3209 & Q=5,3300 \\ \text { A D B } & 1,0884 & Q=4,0130 \\ \text { B D A } & 0,9362 & Q=3,7775\end{array}$

Ao nível de $1 \%$

$\begin{array}{llll}\text { A } & 0,9684 & Q=5,8400 \\ \text { B } & 0,5181 & Q=4,6750 \\ \text { B } & & 0,8158 & Q=5,5000 \\ \text { A * B } & 1,5273 & \text { Q }=6,1625 \\ \text { A D B } & 1,3237 & Q=4,8804 \\ \text { B D A } & 1,1586 & \text { Q }=4,6750\end{array}$

